\title{
Advancing data assimilation in operational hydrologic forecasting: progresses, challenges, and emerging opportunities
}

\author{
Y. Liu ${ }^{1,2}$, A. H. Weerts ${ }^{3}$, M. Clark ${ }^{4}$, H.-J. Hendricks Franssen ${ }^{5}$, S. Kumar ${ }^{6,2}$, H. Moradkhani ${ }^{7}$, D.-J. Seo ${ }^{8}$, \\ D. Schwanenberg ${ }^{3,9}$, P. Smith ${ }^{10}$, A. I. J. M. van Dijk ${ }^{11}$, N. van Velzen ${ }^{12,13}$, M. He ${ }^{14,15}$, H. Lee ${ }^{14,16}$, S. J. Noh ${ }^{17,18}$, \\ O. Rakovec ${ }^{19}$, and P. Restrepo ${ }^{20}$ \\ ${ }^{1}$ Earth System Science Interdisciplinary Center, the University of Maryland, College Park, MD, USA \\ ${ }^{2}$ Hydrological Sciences Laboratory, NASA Goddard Space Flight Center, Greenbelt, MD, USA \\ ${ }^{3}$ Deltares, Delft, The Netherlands \\ ${ }^{4}$ Research Applications Laboratory, National Center for Atmospheric Research, Boulder, CO, USA \\ ${ }^{5}$ Agrosphere (IBG 3), Forschungszentrum Jülich, Jülich, Germany \\ ${ }^{6}$ Science Applications International Corporation, Beltsville, MD, USA \\ ${ }^{7}$ Department of Civil and Environmental Engineering, Portland State University, Portland, OR, USA \\ ${ }^{8}$ Department of Civil Engineering, University of Texas at Arlington, Arlington, TX, USA \\ ${ }^{9}$ Institute of Hydraulic Engineering and Water Resources Management, University of Duisburg-Essen, Duisburg, Germany \\ ${ }^{10}$ Lancaster Environment Centre, Lancaster University, Lancaster, UK \\ ${ }^{11}$ Fenner School for Environment and Society, Australian National University/CSIRO Land and Water, Canberra, Australia \\ ${ }^{12}$ Delft Technology University, Delft, The Netherlands \\ ${ }^{13}$ VORtech, Delft, The Netherlands \\ ${ }^{14}$ Office of Hydrologic Development, National Weather Service, Silver Spring, MD, USA \\ ${ }^{15}$ Riverside Technology, Inc., Fort Collins, CO, USA \\ ${ }^{16}$ University Corporation for Atmospheric Research, Boulder, CO, USA \\ ${ }^{17}$ Department of Urban and Environmental Engineering, Kyoto University, Kyoto, Japan \\ ${ }^{18}$ Water Resources and Environment Research Department, Korea Institute of Construction Technology, \\ Goyang Si Gyeonggi Do, Korea \\ ${ }^{19}$ Hydrology and Quantitative Water Management Group, Wageningen University, Wageningen, The Netherlands \\ ${ }^{20}$ North Central River Forecast Center, National Weather Service, Chanhassen, MN, USA
}

Correspondence to: Y. Liu (yuqiong.liu@nasa.gov)

Received: 2 March 2012 - Published in Hydrol. Earth Syst. Sci. Discuss.: 14 March 2012

Revised: 27 August 2012 - Accepted: 17 September 2012 - Published: 29 October 2012

\begin{abstract}
Data assimilation (DA) holds considerable potential for improving hydrologic predictions as demonstrated in numerous research studies. However, advances in hydrologic DA research have not been adequately or timely implemented in operational forecast systems to improve the skill of forecasts for better informed real-world decision making. This is due in part to a lack of mechanisms to properly quantify the uncertainty in observations and forecast models in real-time forecasting situations and to conduct the merging of data and models in a way that is adequately efficient and transparent to operational forecasters.
\end{abstract}

The need for effective DA of useful hydrologic data into the forecast process has become increasingly recognized in recent years. This motivated a hydrologic DA workshop in Delft, the Netherlands in November 2010, which focused on advancing DA in operational hydrologic forecasting and water resources management. As an outcome of the workshop, this paper reviews, in relevant detail, the current status of DA applications in both hydrologic research and operational practices, and discusses the existing or potential hurdles and challenges in transitioning hydrologic DA research into cost-effective operational forecasting tools, as 
well as the potential pathways and newly emerging opportunities for overcoming these challenges. Several related aspects are discussed, including (1) theoretical or mathematical aspects in DA algorithms, (2) the estimation of different types of uncertainty, (3) new observations and their objective use in hydrologic DA, (4) the use of DA for real-time control of water resources systems, and (5) the development of community-based, generic DA tools for hydrologic applications. It is recommended that cost-effective transition of hydrologic DA from research to operations should be helped by developing community-based, generic modeling and DA tools or frameworks, and through fostering collaborative efforts among hydrologic modellers, DA developers, and operational forecasters.

\section{Introduction}

It is essential to properly characterize and communicate uncertainty in weather, climate, and hydrologic forecasts to be able to effectively support emergency management and water resources decision making (National Research Council, 2006). In hydrology, the importance of accounting for various types of uncertainty involved in the prediction process has been increasingly recognized in recent years (e.g., Pappenberger and Beven, 2006; Schaake et al., 2006; Brown, 2010). Uncertainty in hydrologic predictions can originate from several major sources, including errors in the model structure and model parameters, as well as model initial conditions and hydrometeorologic forcing (e.g., Ajami et al., 2007; Kavetski et al., 2006a, b; Salamon and Feyen, 2010). Effective quantification and reduction of these uncertainties is necessary to enable the generation of forecast products with accurate and actionable guidance on predictive uncertainty to enable risk-based decision making (e.g., Pappenberger et al., 2008, 2011; Thielen et al., 2009; Coccia and Todini, 2011; Weerts et al., 2011). The application of data assimilation (DA), which optimally merges information from model simulations and independent observations with appropriate uncertainty modeling, has proved promising in improving prediction accuracy and quantifying uncertainty (e.g., McLaughlin, 2002; Liu and Gupta, 2007; Reichle, 2008).

Over the last couple of decades, the abundance of new hydrologic observations (in-situ or remotely sensed) has stimulated a great deal of research into the use of these observations for improving hydrologic predictions via model-data infusion applications. Many of these applications rely on assimilating traditional in-situ observations such as discharge, soil moisture and snowpack measurements into hydrologic models to improve predictions of streamflow and other hydrologic variables (e.g., Seo et al., 2003, 2009; Vrugt et al., 2005; Weerts and El Serafy, 2006; Clark et al., 2008a; Komma et al., 2008; Moradkhani and Sorooshian, 2008;
Thirel et al., 2010a, b). In recent years, increasing availability of satellite observations (e.g., van Dijk and Renzullo, 2011) has generated unprecedented research activity into assimilating these remotely sensed retrievals of various quantities, such as soil moisture (e.g., Pauwels et al., 2001; De Lannoy et al., 2007; Moradkhani and Sorooshian, 2008; Reichle et al., 2008; Yirdaw et al., 2008; Crow and Ryu, 2009; Kumar et al., 2009; Brocca et al., 2010; Montzka et al., 2011; Peters-Lidard et al., 2011; Liu et al., 2012), snow water equivalent and/or snow cover area or extent (e.g., Rodell and Houser, 2004; Lee et al., 2005; Andreadis and Lettenmaier, 2006; Liston and Hiemstra, 2008; Zaitchik et al., 2008; Durand et al., 2009; Kolberg and Gottschalk, 2010; Kuchment et al., 2010; DeChant and Moradkhani, 2011a; De Lannoy et al., 2012), surface water elevation (e.g., Alsdorf et al., 2007; Montanari et al., 2009; Neal et al., 2009; Giustarini et al., 2011), terrestrial water storage (Zaitchik et al., 2008) and land surface temperature (Reichle et al., 2010), among others. These DA applications were developed for a variety of models ranging from physically-based land-surface models (e.g., Albergel et al., 2008; Nagarajan et al., 2010) to distributed hydrologic models (e.g., Clark et al., 2008a; Rakovec et al., 2012a, b) and conceptual rainfall-runoff models (e.g., Aubert et al., 2003; Seo et al., 2003, 2009; Moradkhani et al., 2005a, b; Weerts and El Serafy, 2006), hydraulic models (e.g., Shiiba et al., 2000; Madsen et al., 2003; Neal et al., 2007; Schumann et al., 2009; Weerts et al., 2010; Ricci et al., 2011), groundwater models (e.g., Valstar et al., 2004; Franssen et al., 2011), coupled surface-subsurface models (e.g., Camporese et al., 2009), biogeochemical models (e.g., Chen et al., 2009), and sediment transport models (e.g., Stroud et al., 2009). Less well-known is the application of DA in the real-time control or operation of various types of water resources systems (e.g., Bauser et al., 2010; Schwanenberg et al., 2011).

In the meantime, DA algorithms are becoming increasingly sophisticated, from simple rule-based, direct insertion methods to advanced smoothing and sequential techniques as well as the various variants of these techniques. These include, for example, the one-, two-, three- and fourdimensional variational algorithms (1D-, 2D-, 3D-, and 4DVAR, e.g., Seo et al., 2003, 2009; Valstar et al., 2004), extended or ensemble Kalman filtering (EKF or EnKF, e.g., Moradkhani et al., 2005b; Slater and Clark, 2006; Weerts and El Serafy, 2006; Shamir et al., 2010), particle filtering (e.g., Moradkhani et al., 2005a; Weerts and El Serafy, 2006; Matgen et al., 2010; DeChant and Moradkhani, 2012), H-infinity filters (Wang and Cai, 2008), hybrid EnKF or 4D-VAR approaches (e.g., Zhang et al., 2009), and other Bayesian approaches (e.g., Reggiani and Weerts, 2008; Todini, 2008; Reggiani et al., 2009). While most DA applications have focused on updating hydrologic model states (e.g., soil moisture and snow water equivalent), recent research has also examined the benefits of estimating model states and model parameters simultaneously (e.g., Moradkhani et al., 2005a, b; 
Vrugt et al., 2005; Franssen and Kinzelbach, 2008; Lu et al., 2010; Leisenring and Moradkhani, 2011; Nie et al., 2011) as well as the possibility of model structure identification and uncertainty estimation (e.g., Neuman, 2003; Bulygina and Gupta, 2010; Hsu et al., 2009; Parrish et al., 2012).

It is worth noting that many of the hydrologic DA studies reported in the literature focused on advancing the theoretical development of DA techniques using, for example, identical or fraternal twin synthetic experiments (e.g., Andreadis et al., 2007; Kumar et al., 2009; Crow and Ryu, 2009). This is especially the case when it comes to assimilating satellite data. The synthetic experiments are useful for diagnostic and design purposes such as assessing the impact of improper characterization of model and observation errors (e.g., Crow and Van Loon, 2006; Reichle et al., 2008) and evaluating the potential benefits of future satellite missions (e.g., Matgen et al., 2010). Nevertheless, despite the overwhelming research into hydrologic DA, only a few studies (e.g., Seo et al., 2003, 2009; Thirel et al., 2010a, b; Weerts et al., 2010; DeChant and Moradkhani, 2011a, 2011b) formulated DA in an operational setting and attempted to evaluate the performance gain from DA in a forecast mode (e.g., as a result of better characterized initial conditions). The application of advanced DA techniques for improving hydrologic forecasts by operational agencies is even rarer, especially when it comes to assimilating new observations from multiple sources across a range of spatiotemporal scales. In operational practice, the correction of model inputs, states, initial conditions and parameters is often conducted in a rather empirical and subjective way (Seo et al., 2009). Generally speaking, hydrologic DA as an objective tool for reducing predictive uncertainty is not yet technically ready for operational hydrologic forecasting and water resources management. This is due in part to a lack of mechanisms to properly quantify the uncertainty in observations and forecast models in real-time forecasting situations and to conduct the merging of data and models in a way that is adequately efficient and transparent to operational forecasters.

Nevertheless, the need for implementing effective DA in the forecast process to bridge the immense gap between the theory and operational practice is increasing. For example, Welles et al. (2007) reported that the hydrologic forecasting skill for some river basins at the US National Weather Service (NWS) River Forecast Centers has hardly improved over the past decade, with above flood-stage hydrologic forecasts beyond three days having very poor skill. This highlights the potential, as well as the need, of assimilating new observations into the operational hydrologic forecasting process to improve the predictive skill and extend the forecast lead time. For many parts of the world, remotely-sensed observations (e.g., satellite images) are the only observations available and their optimal use in hydrologic forecasting via DA needs to be fully explored (National Research Council, 2007). In meteorological and atmospheric sciences, steady improvements in numerical weather forecasting and climate prediction over the last couple of decades have been enabled to a certain degree by the development of community-based models and DA systems (e.g., Pappenberger et al., 2011). In the meantime, while satellite DA has not been adequately explored in operational hydrology, the improvement of performance in operational weather forecast has been attributed (at least partially) to the incorporation of satellite data whose quality and spatiotemporal resolutions have been steadily improving in recent years (Rabier, 2005; Reichle, 2008). The hydrologic community should learn from the experiences of the meteorological and atmospheric communities by accelerating the transition of hydrologic DA research into operations to better utilize new observations and by developing community-supported, open-source modeling systems (e.g., Werner et al., 2012; McEnery et al., 2005) and DA tools (e.g., van Velzen and Verlaan, 2007; Kumar et al., 2008b; Weerts et al., 2010).

It is important to note that in addition to community support and the use of new sources of data (e.g., satellite-based products), other factors may have also contributed to the apparently greater advances of DA in operational meteorology than in operational hydrology. These include, among other reasons, the differences in the underlying physical system (i.e., atmospheric vs. land/hydrologic systems), types of data and procedures used by the forecasting systems as well as other historical/societal reasons, such as more funding and higher relevance of good forecasts (e.g., for aviation and military) for operational meteorology. For example, in contrast to developments in operational meteorology, developments (in both science and technology) in operational hydrologic forecasting have taken place more on a local, national and regional (e.g., in the case of trans-boundary rivers) rather than multinational or international scale. Also, hydrologic forecasting systems often employ workflows with numerous models that represent different processes, all linked together to provide the best forecast for the up- and downstream locations. This has rendered it less straightforward to apply consistent automated DA procedures across the hydrologic forecasting systems. It is also interesting to note that historic developments have led to a difference in the hydrologic forecast paradigms in the US and Europe. In the US, the flood forecasting procedure used by the NWS River Forecast Centers has traditionally involved manual modifications (MODS; see for instance Seo et al., 2003; Smith et al., 2003) of parameters and states and this is still the case. While in Europe, flood forecasting procedures include more automated adjustments to the hydrologic forecasts, likely due to the fact that in Europe upgrades of flood forecasting systems have taken place since the early 2000s (see for example Werner et al. $(2009,2012)$ that describe some of the developments in flood forecasting systems/procedures). Currently, hydrologic operational centers across Europe apply automated methods like autoregressive-moving- average (ARMA) or error correction methods, deterministic updating methods (e.g., Moore, 2007), statistical (or post-processing) 
correction techniques, and to a much lesser degree ensemble data assimilation methods like the EnKF.

The assimilation of various types of observations into operational hydrologic forecasting offers ample research opportunities and poses substantial challenges such as satellite retrieval algorithm development, bias correction, error estimation, downscaling, model diagnosis and improvement, new DA algorithm development, efficient or effective performance evaluation, computational efficiency enhancement, among others. To address these challenges and identify potential opportunities in the context of improving operational hydrologic forecasting and water resources management via DA, an international workshop was held in Delft, the Netherlands on 1-3 November 2010 (Weerts and Liu, 2011). The overall goal of the workshop was to develop and foster community-based efforts for collaborative research, development and synthesis of techniques and tools for hydrologic DA, and the cost-effective transition of these techniques and tools from research to operations. The workshop was attended by a mix of senior scientists and graduate students from a range of entities including universities, government agencies, operational centers, and nonprofit research institutions from 12 different countries representing 23 different organizations.

This paper reviews the status of DA applications in hydrology from several important aspects and summarizes the discussion and findings from the workshop regarding the progresses, challenges, and opportunities in advancing DA applications in operational forecasting. It is noted that the current paper does not seek to perform a comprehensive assessment of the state of the hydrologic DA research; rather, it presents the knowledge, experience, and best judgments of the workshop participants in relevant areas of applying DA to operational hydrologic forecasting and water resources management, and makes corresponding recommendations for advancing these applications (where possible or relevant). Since DA applications for both hydrologic and land surface models are relevant for operational hydrologic forecasting or water resources management across various spatiotemporal scales, advances in both research areas will be discussed (albeit currently conceptual rainfall-runoff models are more commonly used in operational hydrologic forecasting than physically-based land surface models).

The paper is organized as follows. Theoretical and mathematical aspects of hydrologic DA applications are reviewed in Sect. 2, followed by a discussion on the modeling and quantification of model and data uncertainties in DA applications in Sect. 3. Section 4 discusses the challenges and new opportunities related to the objective utilization of new and existing sources of data (in-situ or remotely-sensed) for hydrologic DA applications. Section 5 is devoted to the discussion of using DA for the real-time control and operation of water resources systems, an area of research and development less well-known to the general hydrologic community. The development and potential benefits of open-source and community-based tools for hydrologic DA is presented in Sect. 6. A summary of the discussions is presented in Sect. 7.

\section{Theoretical aspects}

Broadly speaking, operational hydrologic forecasting presents three types of DA problems. The first is the state updating problem in which data such as stage, streamflow, rainfall, snow water equivalent, snow depth, potential or actual evapotranspiration, soil moisture and piezometric heads are assimilated into lumped or distributed hydrologic, hydraulic or land surface models to update the models' dynamic states. The second is the parameter estimation or optimization problem, referred to often as calibration, in which the data are used to estimate or optimize the model parameters that may be considered static or time-varying. The third, termed the error updating problem, refers to using DA to revise the predictions of an error model representing the difference between the hydrologic forecasts and corresponding observations. These three types of DA problems are not mutually exclusive since a forecasting system can utilize any combination (see e.g., Young, 2002; Moradkhani et al., 2005b). The focus here is largely on the first and third types, while referring the readers to the vast literature on calibration for the second type (e.g., Beven and Binley, 1992; Vrugt et al., 2003).

Below, we briefly review the theoretical basis of the existing DA techniques with the aim of identifying limitations, perceived or demonstrated, for application specifically in operational hydrologic forecasting. We then describe significant challenges from theoretical considerations in applying them in operational hydrologic forecasting.

\subsection{State updating}

The aim of this form of DA is to render the model states (as translated through the model dynamics) consistent with the observations. The most direct form of assimilating data into a model in operational hydrologic forecasting is the manual correction of the internal states of the model by human forecasters based on their expert interpretation of the discrepancy between the recent model simulations and the observed data. While such techniques are widely practiced in operational forecasting, their effectiveness is scantily reported (Seo et al., 2009). It is reasonable to presume that the successful application of such manual techniques requires an experienced forecaster along with an interpretable and preferably simple lumped hydrologic model. The latter condition is considered necessary since it is probably impractical to manually apply hydrologically consistent corrections to a distributed hydrologic model or land surface model without simplifying rules. The formulation of such simplifying rules can be extended to provide an automated system of deterministic DA. Operational examples of such rule-based DA include the Grid2Grid rainfall-runoff model operational in the UK flood 
forecasting centre (Cole et al., 2009) and the probability distributed model (PDM, Moore, 2007) operational in the Environment Agency National Flood Forecasting System, which utilizes a flow partitioning to correct the upstream storage volumes in a grid-based distributed hydrologic model. Other schemes (e.g., Rungo et al., 1989) utilize similar concepts to assimilate data into hydraulic models.

A more common framework is to consider the state space model in Eqs. (1) and (2) (Evensen, 1994; Liu and Gupta, 2007),

$x_{k+1}=M_{k+1}\left(x_{k}, \theta, u_{k+1}\right)+\eta_{k+1}$

$z_{k+1}=H_{k+1}\left(x_{k+1}, \theta\right)+\varepsilon_{k+1}$,

where $M_{k+1}$ represents the forward model that propagates the system states $x$ from time $t_{k}$ to $t_{k+1}$ in response to the model input $u_{k+1}$ (with an error term $\zeta_{k+1}$ ) and parameters $\theta ; H_{k+1}$ is the observation function that relates model states and parameters to observations $z_{k+1} ; \eta_{k+1}$ denotes the model error with mean $\bar{\eta}_{k+1}$ and covariance $Q_{k+1}$; and $\varepsilon_{k+1}$ denotes the observation error with mean $\bar{\varepsilon}_{k+1}$ and covariance $R_{k+1}$. In this notation, the parameter vector $\theta$ is considered to be time invariant and can be determined from either physical principles or parameter calibration. Unknown or time varying parameters can be incorporated into the state vector to form a joint state-parameter estimation problem (e.g., Moradkhani et al., 2005a), with the dynamics of the model parameters usually prescribed by a random walk process in sequential algorithms. Such joint estimation may increase the nonlinearity between the state and observation spaces and exacerbate the computational challenges highlighted in this section. An alternative approach is to conduct dual estimation, where the unknown parameters and model states are estimated separately in a parallel or interactive fashion (e.g., Moradkhani et al., 2005b; Vrugt et al., 2005). The predictive distribution of $z_{k+1}$ (or more generally prediction $n$ time steps ahead $z_{k+n}$ ) arises from the mapping of the stochastic noise terms through Eqs. (1) and (2). The operational usefulness of the forecast summarized by the predictive distribution is dependent upon two main factors. The first of these is the ability of the modeller to appropriately define the distributions of $\zeta_{k+1}, \eta_{k+1}$ and $\varepsilon_{k+1}$ to characterize the various sources of uncertainty, including errors in the model input, measurement errors in the observations, conceptual discrepancies between observed and model states, and the inadequacy of the model in representing the dynamics of the system. The second of these is the computational approximation of the predictive distribution (see relevant discussions below).

For state updating, the state space model outlined above may be solved as a filtering or smoothing problem. For problems with nonlinear $M$ and/or nonlinear $H$, the solution is not trivial. A number of computational techniques are available to provide approximate solutions. The commonly applied methodologies for solving the problem via filtering are nonlinear extensions to the Kalman filter (KF, Kalman, 1960). Three extensions to the KF are widely known, namely, the extended Kalman filter (EKF, e.g., Georgakakos, 1986a, b; Kitanidis and Bras, 1980), ensemble Kalman filter (EnKF, Evensen, 1994) and unscented Kalman filter (UKF, Julier and Uhlmann, 1997). The key difference between the nonlinear Kalman filters lies in the methods of propagating the expected value and covariance of the state space though the nonlinear operators $M$ and $H$. The EKF linearizes (sometimes unrealistically) these operators based on local derivatives, which are often difficult to compute reliably; hence, the EKF techniques has fallen out of favour (Da Ros and Borga, 1997). The two remaining techniques propagate the state space using a sample. In EnKF, the state space is presumed to be multivariate Gaussian, while the UKF presumes the state space is unimodal, symmetric and unbound. Despite the more relaxed assumptions of the UKF, it has received little attention in the hydrologic literature to date. The EnKF technique, however, has become the most frequently used DA technique in the hydrologic community, due largely to its easy implementation and its robustness in solving most DA problems encountered in hydrologic applications.

The size of the sample used in the EnKF or UKF may prove computationally burdensome in an operational environment. Typically, hundreds of ensemble members are needed for reliable updating without filter inbreeding (e.g., Franssen and Kinzelbach, 2008), although for land surface problems often smaller ensemble sizes (e.g., less than 100) are used. EnKF has also been applied on large scale problems which involve over $10^{5}$ unknown states and parameters. Another limitation of the EnKF is that its optimal performance is restricted to multi-Gaussian distributed states and parameters. In the operational weather forecasting community, the local ensemble transform Kalman filter (LETKF) was introduced to overcome the issue of prohibitively large dimensionality by solving the analysis independently in a local region around every model grid point using only local observations (e.g., Szunyogh et al., 2008; Ott et al., 2004). Similarly, Sun et al. (2009) applied grid-based localization and a Gaussian mixture model (GMM) clustering technique to improve the performance of EnKF for states and parameters which are not multi-Gaussian distributed. Zhou et al. (2011) illustrated how a normal score transformation for both states and parameters improved the performance of EnKF drastically for bimodal distributed parameter fields. Here, the normal score transformation is made for each time step and each grid cell, using the simulated values from the ensemble to construct space-time specific probability density functions (PDFs). The EnKF is applied on these normal-score transformed values, which are then back transformed based on the established relationships between physical values and normal-score transformed values. It has yet to be investigated in more detail under which conditions, and for which types of problems, such transformations could significantly outperform the classical EnKF. Alternatively, more sophisticated 
transformations could also be explored. For all these extensions, $\varepsilon_{t+1}$ and $\eta_{t+1}$ are considered symmetric, unimodal, and unbounded zero-mean random variables which are independent (both in time and of each other). This means that great care should be taken in constructing $M$ and $H$ if there is belief that systematic biases or phase errors in the data or model exist (e.g., Dee, 2005; Crow and Van Loon, 2006). It is also noted that the common assumption that the distribution of the states is unbounded is rarely satisfied in real-world problems; hence some mathematical transformation is often necessary.

Another flexible (but potentially more computationally expensive) approach to solving the above filtering problem includes the sequential Monte Carlo (SMC) methods such as particle filtering (PF) (e.g., Arulampalam et al., 2002; Moradkhani et al., 2005a; Weerts and El Serafy, 2006; Noh et al., 2011; Plaza et al., 2012). Similar to the EnKF, particle filtering evolves a sample of the state space forward using the SMC method to approximate the predictive distribution. However, unlike the KF-based methods, PF performs updating on the particle weights instead of the state variables, which has an advantage of reducing numerical instability especially in physically-based or process-based models. In addition, $\mathrm{PF}$ is applicable to non-Gaussian state-space models. Earlier implementation of the particle filtering relied on sequential importance sampling (SIS) which would result in sample degeneracy (where most of the particles converge to a single point). To alleviate this problem, sampling importance resampling (SIR) could be used (e.g., Moradkhani et al., 2005a). Synthetic studies in other fields (e.g., Liu and Chen, 1998; Fearnhead and Clifford, 2003; Snyder et al., 2008) showed that PF often needs more particles than other filtering methods and the required ensemble size can increase exponentially with the number of state variables. Typically, even for small problems with only a few unknown states and parameters, hundreds or thousands of ensemble members may be needed for reliable characterization of the posterior PDF. Further exploration is needed to test the PF for problems with thousands of unknown states and parameters. Although PF may outperform EnKF when the number of particles is larger than a hundred in the case of conceptual hydrologic models (Weerts and El Serafy, 2006), the number of particles required for physically-based distributed hydrologic models may limit operational applications of PF. Fortunately, the recent development by Moradkhani et al. (2012) shows that, by combining PF with Markov Chain Monte Carlo (MCMC), improved performances for state-parameter estimation may be achieved with small, manageable ensemble sizes. Also, DeChant and Moradkhani (2012) showed that when properly coded and implemented PF can be computationally even more efficient than the EnKF and is more effective and robust for joint state-parameter estimation.

The above techniques rely on approximating the evolution of the distribution of the unknown model states over time. A number of variational DA techniques (e.g., Li and
Navon, 2001), which can be viewed as simplifications of the KF (since they do not propagate the state covariance matrix explicitly) have been used operationally, primarily in the numerical weather prediction community (see e.g., Fischer et al., 2005; Lorenc and Rawlins, 2005). In hydrology, Seo et al. $(2003,2009)$ explored the use of variational DA in experimental operational streamflow forecasting and demonstrated large potential gains over manual runtime adjustments during operations. Lee et al. $(2011,2012)$ explored the use of variational methods for streamflow and/or soil moisture assimilation in a distributed hydrologic modeling framework with a high dimensional state space. The variational techniques can be particularly appealing when the covariance matrix is large (for example, corresponding to more than $10^{5}$ unknown states and/or parameters) such that defining meaningful error covariance matrices is impractical in operational applications.

It is important to note that all DA algorithms rely on the fundamental basis of Bayesian theory for updating the model states or parameters. For a more detailed discussion on the various types of hydrologic DA problems and techniques, the readers are referred to Liu and Gupta (2007).

\subsection{Error updating}

The error updating problem can be thought of as assimilating the latest observation and its corresponding prediction to inform the predictive distribution of the errors in future model predictions with respect to the (to-be) observed data. This is not to be confused with the propagation of the error covariance matrices in state updating applications. Rather, error updating discussed here refers to the use of DA to condition the predictions of an error model representing the difference between an, often deterministic, hydrologic forecast and the corresponding observations (see e.g., Smith et al., 2012, this issue). In other words, data is not assimilated into the hydrologic model with the aim of producing improved forecasts but is used to inform the prediction of future discordances between the model forecast and future observations. Operational examples include the use of ARMA time series models to describe transformed residuals in flood forecasting system (e.g., Broersen and Weerts, 2005) and a stochastic multiplicative correction (e.g., Lees et al., 1994; Smith et al., 2012, this issue). In both these cases, predictions can be computed using linear filtering. A wide variety of alternative error models may be found in the literature (Seo et al., 2006; Weerts et al., 2011; among others) and the problem may be formulated in a Bayesian context (e.g., Krzysztofowicz and Maranzano, 2004).

To effectively utilize error updating to produce reliable forecasts (in both the probabilistic and pragmatic sense), the error model must provide an appropriate description of the difference between the observations and model predictions. Systematic or temporally varying bias must be removed as much as possible. This may prove particularly challenging 
if it is induced by forecasted forcing such as precipitation. Many error models rely on temporal correlation within the residuals. Such correlations may, however, be low at key locations such as the rising limbs of hydrographs (Todini, 2008). As such, error modeling should consider flow dependence of the correlation structure. Also, extreme situations such as floods may reveal previously unknown shortcomings in the hydrologic or hydraulic models. In such situations it may be questionable if the error model continues to be an appropriate description of the difference between the observations and model predictions.

\subsection{Challenges and opportunities}

Besides the challenges discussed above, many other theoretical difficulties are present and need to be effectively addressed. First of all, land surface and rainfall-runoff processes are highly nonlinear and their mathematical models are often not continuously differentiable. Also, the soil moisture states of a model are rarely, if ever, observed directly in the real world, and hence their departures from reality may only be inferred from observations of stage or streamflow, or satellite-based microwave observations. The river stage, for example, is a product of spatiotemporal integration of not only snow accumulation and ablation, and rainfallrunoff processes but also various hydraulic processes expressed through the morphology of the channel. Given these, it is necessary that the DA techniques for operational hydrologic forecasting be able to handle nonlinear dynamics, nonlinear observation functions, and a mix of amplitude and phase errors that operate over a wide range of spatiotemporal scales (Liu et al., 2011). While progresses have been reported in the literature since the mid-1970s, it is less than clear today as to under what conditions and to what degree the existing DA techniques may be able to handle the different DA problems encountered in operational hydrologic forecasting today.

Precipitation and streamflow, arguably the two most important variables in operational streamflow forecasting, are skewed and heteroscedastic, and accurate statistical modeling of their measurement uncertainties is still a challenge. Also, to benefit from accurate modeling of the measurement uncertainty, the uncertainty in the model dynamics and physics will have to be modeled with comparable accuracy. It is expected, however, that there is a practical limit to the complexity of such uncertainty modeling (see more detailed discussion on modeling of uncertainties in Sect. 3). As with any optimal estimation techniques, the optimality of the DA techniques is realized only if the observations and the models are not biased in the mean sense. As such, bias correction must precede or accompany DA to realize the purported optimality (e.g., De Lannoy et al., 2007; Ryu et al., 2009). As described above, the DA problem for state updating may involve multiple model components, such as those for rainfallrunoff, evapotranspiration, snow, and hydrologic or hydraulic routing, that may operate over a wide range of spatiotemporal scales, with each model component contributing a different degree of freedom at its own dominant scale to the overall problem. Directly solving such a large DA problem may be impractical, and it may be necessary to decompose it into smaller problems, but without compromising the quality of the solution in any significant way.

For operational forecasting, performance for extreme events is of particular importance. It is in such infrequently observed events when the mathematical DA techniques may prove superior to purely statistical techniques, which require sizable historical data. Broadly speaking, statistical techniques may be seen as an extreme end of mathematical DA where statistical models are used to describe the dynamics. Optimally balancing physical-dynamical and statistical modeling in DA under different hydrologic conditions, e.g., from drought to flooding, is a complex question that requires much additional research. Since extreme events naturally occur rarely, the ability to assess the usefulness of DA in improving the forecasting of extreme events may be limited by the length of available record. This situation is exacerbated if the system being forecasted has undergone or is undergoing significant changes such that the relationship between the observations and the model output cannot be believed to be constant in time (or space). Caution should therefore be applied in making too strong an assumption about the properties of any DA scheme. Also, with such limitations, it is apparent that the optimal DA scheme (as judged against some criteria that the modeller can assess) derived from the historic data may not be optimal for forecasting into the future.

\section{Modeling of uncertainties}

Model simulations or predictions are subject to various uncertainties and sources of forecast errors. Uncertainties may stem from model initialization, due to incomplete data coverage, observation errors, or an improper DA procedure. Other sources of uncertainty in prediction are associated with model input (i.e., forcing data) and imperfection of the model structure itself, due to the parameterization of physical processes or unresolved scale issues. Even with an assumption of having a perfect model structure, the estimates of model parameters could also be uncertain given the observational uncertainties that affect the model calibration. Therefore, the "optimality" of a DA scheme depends critically on the reliability of error estimates for the inputs and the model itself, as well as proper consideration of interdependencies and interaction of the uncertain model components and/or observations (e.g., Crow and Van Loon, 2006; Moradkhani et al., 2006; Hong et al., 2006). This is because the weight assigned to observations in a DA scheme is computed based on estimates of the relative error in the model and in the observations. The discussion now turns to critically examine different methods to estimate these errors. 


\subsection{Uncertainty in model inputs - the problem of precipitation}

Precipitation is often viewed as the most uncertain model input (e.g., Huard and Mailhot, 2006; Kavetski et al., 2006a, b; Bárdossy and Das, 2008; Renard et al., 2010). This is because precipitation typically has short correlation length scales (in both space and time), and the reliability of basinaverage (or gridded) precipitation estimates is constrained by the poor spatial representativeness of most station networks (e.g., Willems, 2002; Clark and Slater, 2006; Bárdossy and Das, 2008; Villarini and Krajewski, 2008; Volkmann et al., 2010). The uncertainty in precipitation is difficult to reduce, as alternative methods for estimating precipitation, such as radar, satellite, and numerical weather prediction models, have errors that are at least as large as those in many operational station networks (e.g., Hossain and Huffman, 2008; Volkmann et al., 2010), and substantial errors in basin-average rainfall still exist in well-instrumented watersheds. Given the impact of errors in precipitation on the model response (e.g., Bárdossy and Das, 2008), obtaining more reliable estimates of precipitation uncertainty is critical to the success of DA applications.

In a DA context, uncertainty in precipitation is quantified either by stochastically perturbing the precipitation inputs or through conditional simulation methods. The stochastic perturbation approach is the most common (e.g., Steiner, 1996; Crow and Van Loon, 2006; Pauwels and De Lannoy, 2006; Weerts and El Serafy, 2006; Clark et al., 2008a; Komma et al., 2008; Turner et al., 2008; Pan and Wood, 2009). In this approach the size of the precipitation perturbations is typically based only on order-of-magnitude considerations. For example, Reichle et al. (2002) assumed the standard deviation of precipitation errors is equal to $50 \%$ of the precipitation total at each model time step. However, uncertainty in precipitation estimates tends to vary both spatially and temporally (e.g., Tian and Peters-Lidard, 2010; Sorooshian et al., 2011), and therefore estimates of precipitation uncertainty from such order-of-magnitude based approaches may be statistically unreliable. Conditional simulation methods, which condition precipitation estimation on observations of precipitation (e.g., from a station network; see Rakovec et al. (2012b, this issue) for an example on this) and/or other information (e.g., topography), have the potential to provide more reliable uncertainty estimates (e.g., Clark and Slater, 2006; Götzinger and Bárdossy, 2008). For example, the regression-based ensemble spatial interpolation methods used by Clark and Slater (2006) provide an error estimate (i.e., the spread of the precipitation ensemble) that is connected to the error in the regression equations. This approach - and others, such as geostatistically based conditional simulation techniques (Götzinger and Bárdossy, 2008) - provides statistically reliable precipitation ensembles by explicitly linking the error in precipitation estimates to the adequacy of the station network. While conditional simulation methods can be data-intensive to parameterize and computationally expensive to run (McMillan et al., 2011), their potential to provide statistically reliable uncertainty estimates suggests that the implementation costs may be worthwhile.

In large-scale hydrologic modeling and DA applications, statistically reliable quantitative precipitation estimates (QPEs) may need to be generated based on outputs from numerical weather prediction (NWP) models, often aided with other available sources of precipitation information (e.g., stations, radars, and satellites). Statistical post processing (e.g., downscaling and bias correction) of NWP-based precipitation estimates is commonly practiced to close the scale gap between NWP outputs and hydrologic applications and to reduce the systematic bias in the NWP precipitation estimates, while at the same time reproducing the observed local-scale space-time variability in precipitation and other forcing variables (e.g., Clark et al., 2004a, b; Piani et al., 2010; Rojas et al., 2011). Ehret et al. (2012) however cautioned the use of bias correction on precipitation and other outputs from global and regional circulation models for hydrologic applications and propose that improving the simulations from these models (e.g., via increased resolutions and ensemble predictions) is the most promising solution for reducing the uncertainty in precipitation predictions from these models.

\subsection{Uncertainty in the model itself}

Here we define a model as a simplified representation of reality, in which the structure of the model includes the selection of model equations and the time stepping scheme used to integrate the model equations forward in time (e.g., Clark and Kavetski, 2010). Model structure uncertainty is associated with the assumptions that act on the development of the model conceptualization and mathematical structure. An unfortunate truth in model development is that no matter how many resources are invested in developing a particular model, there remain conditions and situations in which the model is unsuitable to give accurate forecast. Many of the model equations contain adjustable parameters that provide scope to apply the model in different regions, and/or to improve the model predictions - for example, hydraulic conductivity can be adjusted to represent different soil types and/or to compensate for the reality that the Richards model equation is often applied at a spatial scale that is much larger than the scale at which the model equation was derived. In this context model error (or model adequacy) is the fidelity of the model response to external forcing, and includes both errors in the model structure (the equations and time stepping scheme) and errors in the model parameter values. Quantifying model error is an extremely difficult proposition, because the many different sources of uncertainty in a model interact in complex ways. The community has adopted four main approaches to quantify model error (as discussed below).

The first approach, and similar to the stochastic perturbation approach for precipitation, is to stochastically perturb 
the model state variables (e.g., Reichle et al., 2002; Vrugt et al., 2006; Clark et al., 2008a). Again, these perturbations are based on order-of-magnitude considerations, and may therefore be statistically unreliable. This approach addresses the model uncertainty term $\eta$ in Eq. (1) by adding random perturbations to the model physics, while the other three approaches to be discussed below aim to represent the model uncertainty through quantifying the uncertainties in model parameters and/or the model structure with more sophisticated approaches (in addition to adding random perturbations).

The second approach is to use inverse methods to infer probability distributions for each model parameter (e.g., Beven and Binley, 1992; Vrugt et al., 2003). However, in this approach it is typically assumed that the initial condition, model structure and the model inputs are perfect, which can lead to model parameters being tweaked to unrealistic values to compensate for errors in model structure and model inputs (Thyer et al., 2009). Moreover, the inverse problem is often poorly constrained, which can result in parameters in one part of the model assigned unrealistic values to compensate for unrealistic parameters in another part of the model (Beven, 2006). Such unrealistic inference of probability distributions of model parameters can lead to situations where the right answers are obtained (e.g., reasonable total uncertainty estimates) for all of the wrong reasons. In the groundwater hydrologic community, attempts have been made to address these parameter identifiability issues via Monte Carlo type inverse modeling techniques, which apply 4D-VAR techniques on a large number of stochastic realizations of one or more spatially distributed parameter fields (Sahuquillo et al., 1992; Franssen et al., 2003).

The third approach is to modify the states and parameters simultaneously and quantify the uncertainty associated with them all within a sequential (or recursive) DA framework (e.g., Moradkhani et al., 2005b; Vrugt et al., 2005; Naevdal et al., 2003). In this approach, the real time updating of state variables and parameter values allow the model to more closely reproduce the observed system response given the updating procedure implemented (i.e., linear updating in ensemble Kalman filtering vs. sequential Bayesian updating and resampling in particle filtering) at each observation time (Moradkhani and Sorooshian, 2008). Various applications of such methods in streamflow forecasting, soil moisture, snow water equivalent estimation, groundwater flow modeling and flood inundation mapping have been reported (e.g., Franssen et al., 2008; Matgen et al., 2010; Leisenring and Moradkhani, 2011; Montzka et al., 2011).

The fourth and final approach to quantify model error is to use multi-model ensembles (e.g., Georgakakos et al., 2004). However, obtaining reliable uncertainty estimates with multimodel ensembles relies entirely on chance. The selection of individual models in the multi-model ensemble is habitually rather ad hoc, with insufficient attention given to whether the differences among the individual models represent the uncer- tainty in simulating natural processes. Many models share a similar heritage, and it is common for different models to get the wrong answers for the same reasons.

\subsection{Challenges and opportunities}

As discussed above, our capabilities for quantifying model error show still important deficits. This section outlines the major challenges and suggests some potential ways in which we as a community can improve uncertainty estimation.

\subsubsection{Disentangling different sources of uncertainty}

A fundamental challenge for quantifying errors in model inputs and in the model itself is that the different error sources are extremely difficult to disentangle (e.g., Kuczera et al., 2006). This includes the uncertainty with respect to the values for a large number of different parameters, possibly showing a mutual strong correlation, as is typically the case for land surface models. Indeed, many attempts to estimate model error effectively lump together different sources of error. For example, the probabilistic parameter inference methods, such as the generalized likelihood uncertainty estimation (GLUE) methodology, the Shuffled Complex Evolution Metropolis (SCEM) algorithm and many of the inverse modeling methods in vadose zone and groundwater hydrology, effectively map all sources of model uncertainty onto the model parameters (Beven and Binley, 1992; Vrugt et al., 2003).

There are a few promising approaches to disentangle the different sources of uncertainty. The first is the simultaneous optimization and data assimilation (SODA) algorithm, in which sequential DA methods are used as part of the probabilistic parameter inference (Vrugt et al., 2005). In this case, stochastic state perturbations and state updates are used to account for model error, reducing the extent to which model error contaminates the inference of the model parameters (e.g., Clark and Vrugt, 2006). The second approach is the Bayesian Total Error Analysis (BATEA) methodology, which specifies error models for all sources of uncertainty and uses available data to refine the error models (Kavetski et al., 2006a, b; Kuczera et al., 2006). The effectiveness of BATEA critically depends on the availability of informative prior information for each individual source of uncertainty (Renard et al., 2010). Given the potential for different sources of uncertainty to compensate for each other (e.g., Crow and Van Loon, 2006), the inference problem may be ill-posed (e.g., Kuczera et al., 2006). The third approach is the online dual state and parameter estimation within a DA framework (e.g., Moradkhani et al., 2005b). As demonstrated in various studies (Franssen and Kinzelbach, 2008; DeChant and Moradkhani, 2012), these methods rely on sequential Bayesian estimation that seems better able to benefit from the temporal organization and structure of information content in the data, achieving better conformity of the model 
output with observations. Moreover, such an approach considers the interdependencies among state variables and parameters concurrently given the highly interactive nature of these model components. Recent development by Moradkhani et al. (2012) and Leisenring and Moradkhani (2012) show how DA using PF combined with MCMC and variable variance multiplier (VVM) can considerably enhance the accuracy of online state-parameter estimation with more reliable quantification of uncertainty. We anticipate that further developments in all of these areas will improve capabilities to produce more meaningful uncertainty estimates.

\subsubsection{Constraining the inference problem}

Another challenge - as mentioned above - is that inverse methods for parameter inference are often poorly constrained, resulting in unrealistic parameter values. The objective functions typically used for parameter inference are based on aggregate measures of model performance (e.g., the sum of squared differences between simulated and observed streamflow), and the individual components of the model are rarely subject to scientific scrutiny (Kuczera and Franks, 2002; Gupta et al., 2008; McMillan et al., 2011). The inference of the different sources of uncertainty can therefore be improved through more intelligent use of the available data (e.g., Gupta et al., 1998, 2008), for example, by separately examining amplitude and phase errors (e.g., Liu et al., 2011).

\subsubsection{Generating efficient multivariate ensembles}

Although not commonly practiced, parameter uncertainty may be accounted for in DA by generating an initial parameter ensemble. However, given the complex interrelationships among model parameters, it can be a challenge to efficiently sampling from multivariate distributions (e.g., of multiple uncertain soil and vegetation parameters) in hydrologic applications to generate parameter ensembles that are physically and dynamically consistent. Similar challenges may exist for generating multivariate forcing ensembles (e.g., for precipitation and temperature). Therefore, further research into developing appropriate multivariate statistical methods for hydrologic parameters and forcing variables should improve our ability to address relevant uncertainties in DA applications.

\subsubsection{Constructing reliable multi-model ensembles}

The multi-model ensemble strategy is a means to address model structure uncertainty by synthesizing outcomes from multiple models representing different parameterizations of underlying physical processes and has been demonstrated to offer better predictability (Hagedorn et al., 2005). The success of a multi-model strategy requires constructing a reliable model ensemble such that the differences among the individual models represent the uncertainty in simulating natural processes. This can be accomplished by using multi-physics model toolboxes such as the Framework for Understanding Structural Errors (FUSE) approach, which provides an effective means to construct multiple unique models by combining the different options for the model architecture and the flux equations (Clark et al., 2008b). For example, to develop an empirically-based surface water model, multiple options are available for the choice of state variables in the unsaturated and saturated zones, as well as the choice of flux equations describing surface runoff, interflow, vertical drainage from the unsaturated zone, base flow, and evaporation (Clark et al., 2008b). Niu et al. (2011) recently reported a similar multi-parameterization approach within the Noah land surface model framework (Noah-MP).

It is important to note that, although the multi-model ensemble approach is widely known to increase predictability, a model ensemble (e.g., developed with the options provided by the multi-model or multi-parameterization frameworks discussed above) may not represent a complete sampling of the model space. One typical challenge involved in such an approach is then concerned with understanding the dependence or independence among the models, as well as the relationship between the model spread and the total predictive uncertainty. Based on the notion of conditional bias, Abramowitz and Gupta (2008) introduced an innovative "model space" metric that allows measuring the distance between models in a theoretical model space, thus helping to quantify how much independent information each model is contributing to representing the predictive uncertainty. Another typical challenge in a multi-model ensemble approach is concerned with developing an effective strategy to optimally combine the individual models to achieve enhanced predictive skill and uncertainty estimation. This can be addressed by simple approaches such as equal weighting (Palmer et al., 2000) or optimal weighting (Regonda et al., 2006). Statistically-based approaches such as linear regression (Krishnamurti et al., 1999) and canonical variate analysis (Mason and Mimmack, 2002) can also be employed to improve the predictive skill of multi-model ensembles. Recent investigations into combining the strengths of DA and multi-model ensembles provide another promising opportunity for simultaneously addressing model and data uncertainties (e.g., Parrish et al., 2012). Further developments along these lines should help to enhance the ability to quantify and reduce uncertainties in hydrologic DA applications.

\section{New measurements}

Hydrologic forecasting can potentially benefit from assimilating relevant observations, especially those not used in developing the models. This section discusses the application of several types of newly emerging or still underutilized hydrologic observations and the challenges and opportunities therein. 


\subsection{Remote sensing data}

Recent advances in remote sensing technologies have enabled a large suite of terrestrial observations from satellites and various remote sensing platforms. These observations can be used to derive information on rainfall, evapotranspiration, snow, soil moisture, topography, vegetation dynamics, flooding, and the total water storage, all of which play an important role in the hydrologic cycle. While in-situ measurements contain little information on the spatial variability of these important quantities, remote sensing data provide full spatial information on these variables (albeit sometimes at a very coarse resolution) and hence hold great potential for distributed hydrologic modeling and DA.

\subsubsection{Hydrologic observations from remote sensing}

Remotely-sensed snow observations are among the most investigated measurements in the hydrologic research community. The Rutgers University Global Snow Lab (RUCL) has been generating snow cover measurements at varying temporal and spatial resolutions, from 1966 to present using the snow cover data set of the National Oceanic and Atmospheric Administration (NOAA). Since early 2000, the Moderate Resolution Imaging Spectroradiometer (MODIS) instrument of the National Aeronautics and Space Administration (NASA) has also been providing daily snow maps at a variety of temporal and spatial resolutions (Hall et al., 2002). Passive microwave radiometry-based estimates of snow water equivalent and snow depth from several satellites have been generated in the past $30 \mathrm{yr}$. The Advanced Microwave Scanning Radiometer (AMSR-E) sensor, launched in 2002 on board the Aqua satellite, is the most recent addition to the passive microwave suite of instruments (Kelly, 2009). A blended snow product, known as the Air Force Weather Agency (AFWA)/NASA snow algorithm (ANSA), has also been developed by combining the retrievals from both MODIS and AMSR-E retrievals (Foster et al., 2011). DA of remote sensing snow products has been explored in numerous studies (e.g., Rodell and Houser, 2004; Parajka and Blöschl, 2008; Hall et al., 2010; Kuchment et al., 2010).

Remote sensing products of soil moisture have also become available in recent years. For example, surface soil moisture has been retrieved from a number of passive sensors starting 1978. These include the Scanning Multichannel Microwave Radiometer (SMMR), the special sensor microwave imager (SSM/I), the Tropical Rainfall Measuring Mission (TRMM) microwave imager (TMI), the AMSR-E, the Windsat radiometer (Windsat), the European Space Agency (ESA) Soil Moisture and Ocean Salinity mission (SMOS, Kerr and Levine, 2008), and the Global Change Observation Mission - Water (GCOM-W). In the meantime, soil moisture products have also been available from active sensors starting in 1992, including the Advanced Scatterometer (ASCAT) and the two European Remote Sensing (ERS) satellites (ERS-1 and ERS-2). New sensors, such as the ESA Sentinel-1 mission and the NASA Soil Moisture Active Passive mission (SMAP, Entekhabi et al., 2010), will be launched in the next couple of years. Active and passive microwave surface soil moisture retrievals have been generated (e.g., Jeu, 2003; Owe et al., 2008; Li et al., 2010; Liu et al., 2012) and examined in numerous DA studies, although generally in the context of land surface models used in weather forecasting (e.g., Reichle et al., 2004; Balsamo et al., 2007). Examples of more conventional hydrologic applications also exist and demonstrated skill in improving streamflow estimates (e.g., Pauwels et al., 2001; Parajka et al., 2006; Brocca et al., 2010, 2012). The NASA/German Gravity Recovery and Climate Experiment (GRACE) satellite (launched in 2002) can map Earth's gravity field with enough accuracy to discern month to month changes in the distribution of the total terrestrial water storage on Earth (Tapley et al., 2004). Despite its coarse spatial $\left(<150000 \mathrm{~km}^{2}\right.$ at mid-latitudes) and temporal 10 days or more) resolutions, GRACE has been used to effectively measure changes in groundwater, deep soil moisture as well as snowpack in some DA studies (e.g., Zaitchik et al., 2008; Su et al., 2010; Forman et al., 2012).

Various types of hydraulic information, such as the extent, elevation, slope, mass and velocity of surface water bodies, river discharge, as well as river bathymetry, can also be observed from space (e.g., Alsdorf et al., 2007). For example, surface water extent can be measured with visible sensors such as MODIS and Landsat and by synthetic aperture radar (SAR) imagery; surface water elevations have been measured with radar altimetry on-board the TOPEX/Poseidon (T/P) satellite (Birkett, 1995), the ERS-1 and ERS-2 missions, and more recently the Envisat (Frappart et al., 2006) and Jason1 missions, and the Ice, Cloud, and land Elevation satellite (ICEsat; Schutz et al., 2005), as well as the Shuttle Radar Topography Mission (SRTM) (Farr et al., 2007). The international Surface Water Ocean Topography mission (SWOT) is planned to be launched in 2019 to produce high-resolution observations of water elevations of the Earth surface (Alsdorf et al., 2007). Hydraulic information such as water elevation and its spatial and temporal variability is critical for shortterm hydrologic forecasting, especially during flooding situations. The potential of assimilating space-born water level information for improved discharge and water depth estimation has been explored in a few studies (e.g., Andreadis et al., 2007; Durand et al., 2008; Neal et al., 2009; Matgen et al., 2010; Biancamaria et al., 2011).

In addition, satellite and airborne remote sensing data have also been used to develop model inputs, such as precipitation, land classification maps, digital elevation models, land surface property maps and spatial model parameterizations, and to evaluate the outputs of hydrologic models - some of which are used in operational systems (see van Dijk and Renzullo, 2011 for a review). In summary, there can be little doubt that remote sensing provides information relevant to hydrologic forecasting. 


\subsubsection{Challenges and opportunities}

Operationally, satellite observations have been routinely assimilated into numerical weather prediction models since the early 1970s (Tracton and McPherson, 1977). The first operational remote sensing application in hydrology occurred in the 1980s (Ramamoorthi, 1983). However, despite the recent increasing availability of remote sensing data, their application in operational hydrologic forecasting is still very limited.

Many experimental studies exploring the use of satellite data have been reported in recent literature. However, most such studies either merely referred to the potential or utility of satellite DA, or were focused on the development of approaches to assimilate hydrologic observations into land surface models (LSM) used in numerical weather forecasting. A major difference between LSMs and "conventional" hydrologic models is that the former include a full description of the radiation and coupled surface water and energy balance at diurnal time scales and - when coupled to an atmospheric model - are able to consider the effect of atmospheric transmissivity on sensor observations. These features make it easier to assimilate satellite land surface temperature and microwave brightness temperature observations. A conventional hydrologic model normally requires considerable modifications or extensions to be amenable for assimilating satellite-based observations. This can include, for example, the coupling of a radiative transfer and energy balance model to assimilate remotely-sensed thermal and microwave emissions. One of the first studies attempting assimilation of satellite observations into such a "conventional" hydrologic model was Ottlé and Vidal-Madjar (1994), who used land surface temperature (LST) and Normalized Difference Vegetation Index (NDVI) products derived from Advanced Very High Resolution Radiometer (AVHRR) observations to update a rainfall-runoff model. Houser et al. (1998) was one of the first to use brightness temperature to improve soil moisture estimation in a distributed hydrologic model. More straightforward for hydrologic models is the assimilation of satellite derived products. Published examples include the assimilation of satellite-derived soil moisture, evapotranspiration, vegetation properties and GRACEderived terrestrial water storage (see van Dijk and Renzullo, 2011 for references).

A big challenge in assimilating remotely-sensed hydrologic data is concerned with the "mapping" between observed and modeled variables. The spatial and temporal characteristics of these variables are rarely identical, and therefore aggregation or disaggregation of either (or both) is required. A specific problem arises when the remote sensing resolution is much coarser than that of the model, a particular issue for the assimilation of passive microwave and GRACE observations. As another example, satellite observations of surface radiances may not help estimate hydrologic processes that occur within small areas below satellite resolution (such as runoff from saturated zones). While ap- proaches can and have been developed to deal with such issues (e.g., Zaitchik et al., 2008) they tend to be observation specific and hence not generically available; also, they do not overcome the fundamental lack of information on spatial patterns at scales finer than the observation footprint. This can affect the efficiency of DA when assimilating coarse remote sensing data into relatively high resolution models, presenting both challenges and opportunities for realizing the full potential of DA in such applications. Conceptual "mapping" can also be a problem. For example, most remote sensing soil moisture products reflect the water status of a very shallow top layer of the soil, whereas hydrologic models typically simulate the water storage of a deeper soil column. Appropriate DA approaches for assimilating derived satellite products (e.g., Li et al., 2012) can mitigate but not entirely avoid this limitation. Assimilation of satellite radiance (i.e., brightness temperature) observations may also help to mitigate the conceptual mapping issue and has shown to result in improved atmospheric and hydrologic predictions (e.g., Masahiro et al., 2008; DeChant and Moradkhani, 2011a).

Another challenge is the specification of uncertainty in remote sensing observations, which is a prerequisite for formal DA. Because of a general lack of accurate information on the magnitude and structure of these errors, usually simplistic assumptions are made. This is a pragmatic solution but can lead to large errors. Such errors are more likely if retrieved variables (e.g. soil moisture) are used rather than primary observations (e.g., brightness temperature). This pleads for the assimilation of primary data, which however shifts the potential for inappropriate error specification to the biophysical and observation models. A promising intermediary approach might be to produce spatially and temporally explicit error estimates, either as part of the remote sensing product retrieval process (Pathe et al., 2009) or through statistical comparison to alternative estimates where errors are independent (Dorigo et al., 2010; Tian and Peters-Lidard, 2010; Liu et al., 2012). The limited life time and changing sensor characteristics of subsequent satellite missions (e.g., those for measuring surface soil moisture discussed in Sect. 4.1.1) also poses a challenge. Uncertainty in future data availability and characteristics affects the operational prospects of DA (although ASCAT is now assimilated in some weather forecasting models; Dharssi et al., 2011). Fortunately, these constraints have been relaxed by the development of simple but robust methods to merge successive active and passive retrievals into a single harmonized product in a way that is easily extended to future missions (e.g., Liu et al., 2012).

Finally, the engineering requirements and infrastructure required for operational satellite DA are currently probably prohibitive for many applications. For example, the observation matrix might become very large for remote sensing data, making inversion of the observation matrix a challenge. Also, parameter optimization and state updating can introduce considerable computational overheads, even more so when large satellite data volumes are involved and iterative 
solution is required. In these cases, the LETKF method (Ott et al., 2004) used in the meteorological community may represent a viable candidate for dimension reduction to facilitate implementation in operational hydrologic forecasting. The current generation of computing infrastructure in most operational weather forecast centers can support intensive calculations required by satellite DA. Most operational hydrologic forecast centers, however, lack the required computing support to implement such intensive calculations. Moreover, there is currently no computer software to support spatiotemporal grid-based DA to the extent that it only requires "minor" software engineering investment to achieve the coupling of models, data, DA techniques and exploitation of high performance computing solutions in the operational forecasting process. Several potential components of a future solution have been or are being developed, through such initiatives as the Land Information System (Kumar et al., 2008a, b), OpenMI (www.openmi.org) and OpenDA (www.openda.org). More discussion on these communityoriented softwares is included in Sect. 6.

In summary, some of the main challenges to successful assimilation of remote sensing data in hydrologic forecasting are related to the model extensions required, the mapping of observations to model variables, the specification of model and observation errors, and - for operational implementation - near-real time access to remote sensing data services and the design and configuration of operational DA systems. Considering these challenges, it is perhaps not surprising that there are currently few hydrologic operational systems that have cleared all these hurdles successfully. Nonetheless, with the increasingly rapid progress being made to address these challenges, there is all reason to be optimistic about the future of satellite DA in operational hydrologic forecasting.

\subsection{Other new or underutilized observations}

Besides the remote sensing products discussed above, there are other new or underutilized observations worth of exploration for hydrologic DA applications. Briefly discussed below are two types of such observations: comic ray data of soil moisture and eddy covariance measurements of the turbulent fluxes between the land surface and the atmosphere.

Neutron activity measured by cosmic ray devices provides an interesting new data source for soil moisture contents for the intermediate scale of several hectares (Zreda et al., 2008). Cosmic ray data may hold considerable potential for hydrologic forecasting applications by providing temporally continuous in-situ information on soil moisture content from a larger part of the root zone (up to one meter under dry conditions) over a larger area than time-domain reflectometery (TDR) or other existing probes. However, to properly assimilate these data, various issues remain to be solved, including properly estimating the measurement errors in the soil moisture content data under various conditions. For example, since the neutron intensity is less dependent on soil moisture contents under wet conditions, the cosmic ray measurements under wet conditions are associated with a larger uncertainty.

Eddy covariance data measure the turbulent exchange fluxes (of water, energy, and carbon dioxide) between the land surface and the atmosphere and an extensive global network of eddy covariance "flux towers" now exists (Baldocchi et al., 2001). The assimilation of such data opens an opportunity for improving predictions with land surface models and integrated hydrologic models. An example for parameter estimation can be found in Mo et al. (2008). However, turbulent flux measurements cannot be directly used for assimilation because in general there is an energy balance gap in the data that needs to be corrected before assimilation. Additional complications may arise from non-Gaussian random errors and their dependence on the flux magnitude or even the season, as well as issues related to heterogeneity within the footprint of eddy covariance measurements.

The above observation types overcome some of the spatial scaling issues associated with in-situ hydrological measurements and are helpful in model parameter estimation. However, in the context of DA, these are still essentially local measurements that do not cover the full spatial domain of typical distributed hydrologic model applications. Appropriate DA techniques are needed to infer and use a spatial covariance information from spatially distributed models or ancillary spatial observations (e.g., airborne or satellite data).

\section{DA and real-time control}

\subsection{Background}

Although not well known in the hydrologic research community, DA techniques are also one of the important building blocks of Real-time Control (RTC) applications. Examples of such applications include the definition of minimum releases for reservoirs depending on the reservoir's water level and environmental objectives, and the operation of flood detention basins based on water levels at reference locations (e.g., Castelletti et al., 2008). In RTC applications, a dynamic system of a hydraulic or water resources structure can be defined as a set of state variables driven by a set of inputs, often divided into controlled inputs (or controls) and noncontrolled inputs (or disturbances). The controlled and noncontrolled inputs are analogous to model parameters and inputs for a hydrologic system, respectively. The overall objective of the optimal control of such a system is to determine the controls that will cause the system states to satisfy a set of physical constraints given the deterministic or stochastic disturbances, while at the same time minimizing (or maximizing) some performance criterion (Kirk, 2004).

Traditionally, the common technique for supervisory control of water resources systems is the definition of offline, reactive operating rules that optimizes the controls to minimize cost of operations. An alternative to the offline technique is 
the application of online optimization. The main representative of this approach is Model Predictive Control (MPC), also referred to as Receding Horizon Control (RHC). MPC makes use of a process model of the dynamic system for predicting future trajectories of the state vector over a finite time horizon in order to determine the optimal set of controlled variables by minimizing a cost function. Like hydrologic forecasting, MPC can benefit from proper DA techniques (e.g., Kalman filtering) for improving estimates of the current system states that are the basis for enhanced accuracy in forecasting future system states. A common DA technique jointly used with MPC is the Moving Horizon Estimation (MHE) approach that looks back into the past for updating current system states by modifying historical inputs, states or model parameters. The optimization problem of nonlinear MPC and MHE schemes can be solved by nonlinear programming algorithms such as Sequential Quadratic Programming (SQP) (e.g., Wächter and Biegler, 2006).

A DA-based MPC framework typically adopts either a "simultaneous" or "sequential" approach. In a simultaneous approach, optimization and simulation (with state updating) are performed simultaneously. In a sequential approach, each iteration of the optimization consists of a sequential simulation of the system with an appropriate numerical integration and optimization (or state updating). In this case, the optimization problem has a reduced variable space compared to the simultaneous approach and leads to valid state trajectories in each iteration step of the optimization. Using one or the other approach has certain advantages which are discussed in Diehl et al. (2009).

\subsection{DA applications in MPC}

Although the application of MPC to water resources systems has been subject of research for at least $15 \mathrm{yr}$, stakeholders have been conservative in applying the technique for full automation of their systems. Ackermann et al. (2000) presented one of the early examples on the control of a run-of-river hydropower plant. In this approach, a linearised one-dimensional Saint-Venant model in combination with quadratic objective functions is used for balancing the damping of discharge peaks against the deviation of a water level in the head barrage of the German river Moselle. The approach is reported to be running successfully for more than $10 \mathrm{yr}$. Other applications of MPC to run-of-river hydropower plant were investigated by Glanzmann et al. (2005), and more recently by Setz et al. (2008) and Sahin (2009). Most applications represent the river section by simple pool models, where the need for sophisticated DA methods is relatively low.

Low-land water systems with highly interconnected and highly regulated river and canal networks have been the focus of several studies in recent years and DA-based MPC seems to be a promising candidate for coordinated control of these systems. Van Overloop et al. (2008) present the ap- plication of MPC to the drainage of Dutch polder systems using MHE for state updating. Several DA techniques were applied to the control of a river weir in the Dutch delta of the rivers Rhine and Meuse in Schwanenberg et al. (2011); due to the small extension of the modeled river system, simple autoregressive (AR) error correction models in combination with MHE were found to outperform exclusive state updating techniques. Nelly et al. (2011) compared the use of sequential Kalman filter and sequential particle filter state observer in the context of MPC of irrigation canals. Both approaches appear efficient and robust, in which the Kalman filter is very fast in terms of calculation time and convergence and the particle filter has advantages in handling nonlinear features of the model. Breckpot et al. (2010) and Blanco et al. (2010) applied MPC in combination with MHE to a regional water system in Belgium. Bauser et al. (2010) applied EnKF to update the model states in the real-time control of a groundwater well field, using a groundwater flow-mass transport model and a cost function that was based on fuzzy decision rules and minimized with genetic algorithms. Furthermore, MPC has been used in the short-term decision-support and supervisory control of reservoir systems, as well as the automation of irrigation systems (e.g., van Overloop et al., 2008; Negenborn et al., 2009; Kearney et al., 2011).

\subsection{Challenges and opportunities}

Most MPC implementations above follow the simultaneous approach which reflects the general tradition in control engineering. From the hydrologist's point of view, however, the sequential approach may be more attractive because it decouples simulation and optimization. This enables the usage of the MPC model and its integration scheme also in a simulation mode. No comprehensive analysis is available on the performance of both approaches applied to water resources systems. Therefore, a more elaborated and systematic analysis of different control options in application to water systems should be undertaken.

As in variational DA approaches, most sequential MPC schemes use reverse adjoint modeling for computing the gradient of an arbitrary objective function related to the controlled input (e.g., Schwanenberg et al., 2011). Computational costs, independent of the dimensions of the gradient vector, are in the order of a model simulation itself and enable the operational application of the MPC. Besides its application in MPC or MHE, adjoint modeling has been applied to more sophisticated hydrologic models, e.g., in Castaings et al. (2009) for a first order sensitivity analysis of an overland flow model. We believe that this technique has much unexploited potential in operational flood forecasting, since it provides significantly more information to a user than just simulation results.

There are only a few application of the MHE method as a DA technique for hydrologic models (Linke et al., 2011), likely due to, as for variational methods, the technical 
difficulty of setting up adjoint models. Therefore, suitable technical frameworks for facilitating the implementation of hydrologic models in simulation and adjoint mode, such as that found in Schwanenberg et al. (2011), should be further explored and developed. Another line of research should cover the application of MHE to hydrologic models and its performance comparison with the commonly used DA techniques such as EnKF. Additionally, the integration of uncertain information in the disturbance (inputs) and the process model should be further explored. A relatively simple technique is multiple model predictive control which optimizes a unique control trajectory for a multiple number of disturbances (van Overloop et al., 2008). This however only works in case of relatively close disturbance trajectories. A novel approach without this limitation is the treebased MPC, where a scenario tree is constructed for both the disturbance and control trajectory to enable adaptive controls (Raso et al., 2010). Furthermore, new opportunities for overcoming the challenges encountered in RTC applications (and those in hydrologic forecasting) may start to emerge if the RTC and hydrologic communities work together to learn from each other's experiences in incorporating DA in their relevant applications.

\section{Community-based efforts}

\subsection{Motivation}

Automated DA techniques are widely used in research and operations in areas like meteorology and oceanography. Despite the fact that the Monte Carlo type filters are model independent, most implementations of these DA methods in hydrologic research are custom implementations specially designed for (and integrated with the code of) a particular model. The use of custom implementations has a number of disadvantages. For example, it is very time consuming and expensive to develop and implement customized DA methods and tools for every specific model and application. It is also difficult to reuse these customized DA methods or tools for other models and applications than those they are originally developed or implemented for (i.e., there is an incompatibility or transferability issue). This, to some extent, has hindered the advance of automated DA tools in operational hydrologic forecasting.

As mentioned earlier, the improvement in numerical weather prediction over the last couple of decades has been enabled to a large degree by the development of communitybased, generic modeling and DA frameworks and tools, which can effectively facilitate the transition from research to operations as well as from operations to research. It is expected that operational hydrologic forecasting can benefit from similar community-based research and development efforts. In the hydrologic community, such efforts are starting to emerge, albeit not as mature or established as those in the weather forecasting world. For example, the open serviceoriented infrastructure of the Flood Early Warning System
(Delft-FEWS, Werner et al., 2012) developed at Deltares (http://www.deltares.com) has been adopted by various operational river forecast centers around the world to develop their next generation of operational forecast systems, including the Community Hydrologic Prediction System of the US NWS (McEnery et al., 2005). The need for communitybased efforts had also led to the recent initiative in developing a Community Hydrologic Modeling Platform (CHyMP, Famiglietti et al., 2008) within the context of the Consortium of Universities for the Advancement of Hydrologic Science, Inc (CUAHSI).

One important feature of community modeling is that it supports, through community contributions and feedback, the generic implementation of various models, forcing data sources, parameter data sets, performance evaluation and other tools within a single framework. DA can benefit from similar community efforts by developing generic tools for implementing various DA algorithms and different types of observational data sets, to serve the diverse needs of different DA problems encountered in hydrologic research and operational applications. It is expected that such community-based generic DA tools, when built upon a community modeling framework, can provide an efficient vehicle for advancing operational hydrologic forecasting and DA.

\subsection{Existing or emerging community DA efforts}

One example of integrated modeling and DA systems in land surface hydrology is the Land Information System (LIS) developed at NASA (Kumar et al., 2006, 2008a, b). The LIS is a flexible land surface modeling and DA framework designed to integrate satellite- and ground-based observational data products, various land surface and hydrologic models, and advanced DA techniques to produce optimal fields of land surface states and fluxes. It features a high performance computing infrastructure that provides adequate support for performing computationally intensive data integration and DA applications over user-specified regional or global domains. In atmospheric sciences, a well-known package is the Data Assimilation Research Testbed (DART, http://www.image. ucar.edu/DAReS/DART/). DART is an open-source community framework for DA developed at the National Center for Atmospheric Research (NCAR). It contains advanced EnKF implementations with features like inflation and smoothing. DART has been successfully linked to some large operational models including the Community Atmospheric Model (CAM) and the Weather Research and Forecasting (WRF) regional prediction model (Anderson et al., 2009).

A few other generic libraries exist or have been proposed. Nerger et al. (2005) introduced the Parallel DA Framework (PDAF, http://pdaf.awi.de/trac/wiki) to facilitate the implementation of ensemble DA systems in large-scale geophysical models. It offers a number of efficient parallel implementation of ensemble DA algorithms including the LETKF. In addition, a MATLAB based DA package for 
hydrology was proposed by Drécourt et al. (2006). Recently, van Velzen and co-workers (van Velzen and Verlaan, 2007; van Velzen and Segers, 2010) proposed COSTA, a generic programming environment for DA and model calibration, while El Serafy et al. (2007) and Weerts et al. (2010) developed a user-oriented generic toolbox for DA. Building on these two previous developments, an open source initiative for DA (OpenDA, www.openda.org/joomla/index.php) was launched in 2010 to facilitate the generic implementation of various DA algorithms as well as calibration algorithms.

\subsection{Challenges and opportunities}

For community-based DA efforts, the main challenges that remain are on custom implementations of DA algorithm and the noise and error models as well as computational performance.

Unlike DA, many optimization packages or toolboxes have been developed for generic model calibration and several specifically for hydrological models; a prime example is the Parameter Estimation Toolbox (PEST, Gallagher and Doherty, 2007). The reason for this unbalance between generic tools for calibration and state updating is probably that state updating requires a high level of interaction with the numerical model. Model calibration can often be performed via relatively simple alterations of a model parameter file. One potential means of dealing with the high level interaction between model and DA algorithms is via the use of the open Model Interface (openMI, Moore and Tindall, 2005; Gregersen et al., 2007). The openMI allows models to exchange data with each other on a time step by time step basis as they run, facilitating the modeling of process interactions. This bears similarity with the exchange of model states between model and DA algorithms, although the focus of openMI is normally not to exchange the complete state vectors but geared towards exchange of model states or fluxes at specific locations.

Another challenge in developing generic DA tools lies in the definition of model noise, which often depends on the model and requires a great deal of model specific knowledge and interactions that are difficult to generalize. However, one could argue that this generalization is not necessary, since the model noise description is part of the model itself so that the responsibility of providing the tools and methods for error estimation lies with the model and not with the interfaces that deal with connecting model-algorithm-observations.

Finally, although parallelism can be easily implemented to deal with the heavy model computation needed by the DA algorithm, the optimal parallelization of the DA update algorithm requires a different distribution of the data over the processors (distributing rows of a matrix) than the optimal parallelization of model computations (distributing columns of a matrix). Optimal results are therefore to be expected with a hybrid form of parallelization of the data (Roest and Vollebregt, 2002). Parallel computing is used in DA systems like
DART, PDAF, and OpenDA. DART allows the parallelization of the update algorithm which is useful when a large amount of observations needs to be assimilated. In DART the model steps can be performed in parallel as well, but the data interaction between the model and filter is still sequential by files. PDAF is implemented as an extension to the model code; the update algorithm is therefore parallelized using the same approach as the model without any exchange by files. OpenDA automatically parallelizes the model computations and allows parallel models to be used without file interaction; implementation of the parallelization of the update algorithms is planned for the near future.

\section{Summary and discussions}

The need for transitioning of hydrologic DA research into effective operations has become increasingly recognized in the wake of frequent occurrences of extreme events in recent years and increasing availability of new observations. This paper reviews the current status of DA applications in hydrologic research, and discusses the existing or potential challenges and emerging opportunities in transitioning hydrologic DA research into effective and efficient operational forecasting tools. The discussion focuses on several critical aspects related to hydrologic DA and is briefly summarized below.

Several theoretic or mathematical challenges need to be addressed before hydrologic DA can fully benefit operational forecasting (Sect. 2). Issues include the high nonlinearity in hydrologic processes, the high dimensionality of the state or parameter vectors of hydrologic models, the skewness and heteroscedasticity in the probabilistic distribution of hydrologic variables, the need for impractically large samples in ensemble approaches, and the limited observations of extreme events. Emerging opportunities include localized and transformation-based ensemble approaches and decomposing of the hydrologic forecast system into smaller subcomponents for separate DA solutions. It is recommended that bias correction precede or accompany DA applications.

The success of a DA scheme depends critically on the characterization of uncertainties (Sect. 3). Uncertainty in precipitation can be quantified by stochastically perturbing precipitation inputs or through conditional simulation methods. Determining model uncertainty can be complicated by interactions among uncertainty sources, poorly constrained inference problems, and difficulty in constructing a reliable multimodel ensemble. These issues can be addressed by disentangling uncertainty sources, intelligent use of available data for inverse modeling, using integrated multi-model and multiparameterization frameworks, and combining the strength of DA and multi-model ensembles.

Hydrologic forecasting can potentially benefit from integrating, via DA, newly emerging observations such as remote sensing data (Sect. 4). Some of the difficulties (or emerging 
opportunities) in effectively assimilating these data include, for example, developing proper modifications of an operational hydrologic model to assimilate "raw" satellite data (i.e., radiance observations), constructing proper "mapping" relationships between remotely observed and modeled variables, providing appropriate specification of uncertainty in remote sensing data, and building an efficient computing infrastructure for retrieving remote sensing data to support satellite DA in operational forecasting.

Although less well-known in the hydrologic community, DA has played an important role in real-time control of water resources systems and hydraulic structures (Sect. 5). DA for real-time control is often conducted within a parameter optimization framework and uses optimization-based techniques (rather than sophisticated DA approaches such as EnKF) for state updating. It is recommended that the hydrologic and control communities work together to learn from each other's experiences to more efficiently address issues encountered in DA applications.

Besides the computational and technical aspects already discussed, other operational aspects like transparency and clearness of the outcomes of DA applications are at least as important for the uptake of automated DA methods in operational practice. For operational forecasters who are used to manual interactions with the forecast system, automated DA of the black-box type may be too adventurous a step to take in the short run. Hence, efforts are needed to speed up the operational implementation of automated DA, by enabling the operational control (with manual interaction) over noise models and observations to be used in DA, and developing DA-guided systems, where the DA results will be presented next to the current forecast to guide operational forecasters.

It is important to note that comprehensive and robust verification of DA results is necessary to demonstrate the value of DA for operational forecasting and to build trust in DA among operational forecasters. One important goal of DA in operational forecasting is to provide an improved analysis of the model initial conditions to produce improved hydrologic forecasts. However, the link between the accurate characterization of the initial conditions and the sensitivity of forecast skill at different lead times to this characterization is still uncertain, largely due to lack of proper verification of the potential gain from DA in a forecast context. Some have also argued that statistically based post-processing of hydrologic forecasts may outperform DA, since the latter aims at improving initial conditions that may not have a sufficiently long memory to improve forecast skill at longer lead times. All of these point to the need for robust forecast verification (e.g., Demargne et al., 2010) that will identify and quantify the sensitivity of forecast skill to accuracy of initial conditions and hence help quantify the value of DA for operational hydrologic forecasting.

The various issues described above call for the need of a community-based approach to hydrologic DA, which aims at providing a set of generic modeling, DA, and verifi- cation tools to serve the diverse needs of the community and to facilitate effective and efficient advances through community contribution and feedback (Sect. 6). This also opens a promising pathway for the cost-effective transition of hydrologic DA research into operational forecasting while at the same time facilitating the communication of new hurdles encountered in operational DA back to the research community. In summary, it is recommended that costeffective transition of hydrologic DA from research to operations should be helped by developing community-based, generic modeling and DA tools, and through fostering collaborative efforts among modellers, DA researchers, and operational forecasters.

Acknowledgements. Support for the 2010 data assimilation workshop was provided by the Flood Control 2015 program (http://www.floodcontrol2015.nl), Deltares, and the Office of Hydrologic Development (OHD) of the US NWS. This support is greatly appreciated. Additional funding for the first author was provided by the National Aeronautics and Space Administration (NASA) under Grant NNX08AU51G. We gratefully acknowledge the contribution from the workshop participants, which helped to shape some of the ideas presented in the paper.

Edited by: F. Pappenberger

\section{References}

Abramowitz, G. and Gupta, H.: Toward a model space and model independencemetric, Geophys. Res. Lett., 35, L05705, doi:10.1029/2007GL032834, 2008.

Ackermann, T., Loucks, D. P., Schwanenberg, D. and Detering, M.: Real-time modeling for navigation and hydropower in the River Mosel, J. Water Res. Pl.-ASCE, 126, 298-303, doi:10.1061/(ASCE)0733-9496(2000)126:5(298), 2000.

Ajami, N. K., Duan, Q., and Sorooshian, S.: An integrated hydrologic Bayesian multimodel combination framework: Confronting input, parameter, and model structural uncertainty in hydrologic prediction, Water Resour. Res., 43, W01403, doi:200710.1029/2005WR004745, 2007.

Albergel, C., Rüdiger, C., Pellarin, T., Calvet, J.-C., Fritz, N., Froissard, F., Suquia, D., Petitpa, A., Piguet, B., and Martin, E.: From near-surface to root-zone soil moisture using an exponential filter: an assessment of the method based on in-situ observations and model simulations, Hydrol. Earth Syst. Sci., 12, 1323-1337, doi:10.5194/hess-12-1323-2008, 2008.

Alsdorf, D. E., Rodríguez, E., and Lettenmaier, D. P.: Measuring surface water from space, Rev. Geophys., 45, RG2002, doi:10.1029/2006RG000197, 2007.

Anderson, J., Hoar, T., Raeder, K., Liu, H., Collins, N., Torn, R., and Arellano, A.: The Data Assimilation Research Testbed: a community facility, B. Am. Meteorol. Soc., 90, 1283-1296, doi:10.1175/2009BAMS2618.1, 2009.

Andreadis, K. M. and Lettenmaier, D. P.: Assimilating remotely sensed snow observations into a macroscale hydrology model, Adv. Water Resour., 29, 872-886, 2006. 
Andreadis, K. M., Clark, E. A., Lettenmaier, D. P., and Alsdorf, D. E.: Prospects for river discharge and depth estimation through assimilation of swath-altimetry into a rasterbased hydrodynamics model, Geophys. Res. Lett., 34, 10403, doi:10.1029/2007GL029721, 2007.

Arulampalam, M. S.: A tutorial on particle filters for online nonlinear/non-Gaussian Bayesian tracking, IEEE T. Signal Proces., 50, 174-188, doi:10.1109/78.978374, 2002.

Aubert, D., Loumagne, C., and Oudin, L.: Sequential assimilation of soil moisture and streamflow data in a conceptual rainfallrunoff model, J. Hydrol., 280, 145-161, 2003.

Baldocchi, D., Falge, E., Gu, L., Olson, R., Hollinger, D., Running, S., Anthoni, P., Bernhofer, C., Davis, K., Evans, R., Fuentes, J., Goldstein, A., Kautul, G., Law, B., Lee, X., Malhi, Y., Meyers, T., Munger, W., Oechel, W., Paw, K. T., Schmid, H. P., Valentini, R., Verma, S., Vesala, T., Wilson, K., and Wofsy, S.: FLUXNET: A New Tool to Study the Temporal and Spatial Variability of Ecosystem-Scale Carbon Dioxide, Water Vapor, and Energy Flux Densities, B. Am. Meteorol. Soc., 82, 2415-2434, 2001.

Balsamo, G., Mahfouf, J.-F., Bélair, S., and Deblonde, G.: A land data assimilation system for soil moisture and temperature: an information content study, J. Hydrometeor, 8, 1225-1242, doi:10.1175/2007JHM819.1, 2007.

Bárdossy, A. and Das, T.: Influence of rainfall observation network on model calibration and application, Hydrol. Earth Syst. Sci., 12, 77-89, doi:10.5194/hess-12-77-2008, 2008.

Bauser, G., Hendricks Franssen, H. J., Kaiser, H. P., Kuhlmann, U., Stauffer, F., and Kinzelbach, W.: Real-time management of an urban groundwater well field threatened by pollution, Environ. Sci. Technol., 44, 6802-6807, doi:10.1021/es100648j, 2010.

Beven, K.: A manifesto for the equifinality thesis, J. Hydrol., 320, 18-36, 2006.

Beven, K. and Binley, A.: The future of distributed models: calibration and uncertainty prediction, Hydrol. Process., 6, 279-298, 1992.

Biancamaria, S., Durand, M., Andreadis, K. M., Bates, P. D., Boone, A., Mongard, N. M., Rodríguez, E., Alsdorf, D. E., Lettenmaier, D. P., and Clark, E. A.: Assimilation of virtual wide swath altimetry to improve Arctic river modeling, Remote Sens. Environ., 115, 373-381, 2011.

Birkett, C. M.: The contribution of TOPEX/Poseidon to the global monitoring of climatically sensitive lakes, J. Geophys. Res., 100, 25179-25204, 1995.

Blanco, T. B., Willems, P., Chiang, P. K., Haverbeke, N., Berlamont, J., and De Moor, B.: Flood regulation using nonlinear model predictive control, Control Eng. Pract., 18, 1147-1157, 2010.

Breckpot, M., Blanco, T. B., and De Moor, B.: Flood control of rivers with nonlinear model predictive control and moving horizon estimation, 49th IEEE Conference on Decision and Control, 6107-6112, 2010.

Brocca, L., Melone, F., Moramarco, T., Wagner, W., Naeimi, V., Bartalis, Z., and Hasenauer, S.: Improving runoff prediction through the assimilation of the ASCAT soil moisture product, Hydrol. Earth Syst. Sci., 14, 1881-1893, doi:10.5194/hess-141881-2010, 2010.

Brocca, L., Moramarco, T., Melone, F., Wagner, W., Hasenauer, S., and Hahn, S.: Assimilation of surface- and root-zone ASCAT soilmoisture products into rainfall- runoff modeling, IEEE T. Geosci. Remote, 50, 2534-2555, doi:10.1109/TGRS.2011.2177468, 2012.

Broersen, P. M. and Weerts, A. H.: Automatic error correction of rainfall-runoff models in flood forecasting systems, in Instrumentation and Measurement Technology Conference, IMTC 2005, Proceedings of the IEEE, 2, 963-968, 2005.

Brown, J. D.: Prospects for the open treatment of uncertainty in environmental research, Prog. Phys. Geog., 34, 75-100, doi:10.1177/0309133309357000, 2010.

Bulygina, N. and Gupta, H.: How Bayesian data assimilation can be used to estimate the mathematical structure of a model, Stoch. Env. Res. Risk A., 24, 925-937, 2010.

Camporese, M., Paniconi, C., Putti, M., and Salandin, P.: Ensemble Kalman filter data assimilation for a process-based catchment scale model of surface and subsurface flow, Water Resour. Res., 45, W10421, doi:10.1029/2008WR007031, 2009.

Castaings, W., Dartus, D., Le Dimet, F.-X., and Saulnier, G.-M.: Sensitivity analysis and parameter estimation for distributed hydrological modeling: potential of variational methods, Hydrol. Earth Syst. Sci., 13, 503-517, doi:10.5194/hess-13-503-2009, 2009.

Castelletti, A., Pianosi, F., and Soncini-Sessa, R.: Water reservoir control under economic, social and environmental constraints, Automatica, 44, 1595-1607, 2008.

Chen, J., Hubbard, S. S., Williams, K. H., Pride, S., Li, L., Steefel, C., and Slater, L.: A state-space Bayesian framework for estimating biogeochemical transformations using timelapse geophysical data, Water Resour. Res., 45, W08420, doi:10.1029/2008WR007698, 2009.

Clark, M. P. and Kavetski, D.: Ancient numerical daemons of conceptual hydrological modeling: 1. Fidelity and efficiency of time stepping schemes, Water Resour. Res., 46, W10510, doi:10.1029/2009WR008894, 2010.

Clark, M. P. and Slater, A. G.: Probabilistic quantitative precipitation estimation in complex terrain, J. Hydrometeorol., 7, 3-22, 2006.

Clark, M. P. and Vrugt, J. A.: Unraveling uncertainties in hydrologic model calibration: Addressing the problem of compensatory parameters, Geophys. Res. Lett., 33, L06406, doi:10.1029/2005GL025604, 2006.

Clark, M. P., Gangopadhyay, S., Hay, L. E., Rajagopalan, B., and Wilby, R. L.: The Schaake Shuffle: A method to reconstruct the space-time variability of forecasated precipitation and temperature fields, J. Hydrometeo., 5, 243-262, 2004a.

Clark, M. P., Gangopadhyay, S., Brandon, D., Werner, K., Hay, L. E., Rajagopalan, B., and Yates, D.: A resampling procedure for generating conditioned daily weather sequences, Water Resour. Res., 40, W04304, doi:10.1029/2003WR002747, 2004b.

Clark, M. P., Rupp, D. E., Woods, R. A., Zheng, X., Ibbitt, R. P., Slater, A. G., Schmidt, J., and Uddstrom, M. J.: Hydrological data assimilation with the ensemble Kalman filter: Use of streamflow observations to update states in a distributed hydrological model, Adv. Water Resour., 31, 13091324, doi:10.1016/j.advwatres.2008.06.005, 2008a.

Clark, M. P., Slater, A. G., Rupp, D. E., Woods, R. A., Vrugt, J. A., Gupta, H. V., Wagener, T. and Hay, L. E.: Framework for Understanding Structural Errors (FUSE): A modular framework to diagnose differences between hydrological models, Water Resour. Res., 44, W00B02, doi:10.1029/2007WR006735, 2008 b. 
Coccia, G. and Todini, E.: Recent developments in predictive uncertainty assessment based on the model conditional processor approach, Hydrol. Earth Syst. Sci., 15, 3253-3274, doi:10.5194/hess-15-3253-2011, 2011.

Cole, S. J., Robson, A. J., Bell, V. A., and Moore, R. J.: Model initialisation, data assimilation and probabilistic flood forecasting for distributed hydrological models, in: Geophysical Research Abstracts, 11, EGU2009-8048-3, 2009.

Crow, W. T. and Ryu, D.: A new data assimilation approach for improving runoff prediction using remotely-sensed soil moisture retrievals, Hydrol. Earth Syst. Sci., 13, 1-16, doi:10.5194/hess13-1-2009, 2009.

Crow, W. T. and Van Loon, E.: Impact of Incorrect Model Error Assumptions on the Sequential Assimilation of Remotely Sensed Surface Soil Moisture, J. Hydrometeorol., 7, 421-432, doi:10.1175/JHM499.1, 2006.

Da Ros, D. and Borga, M.: Adaptive use of a conceptual model for real time flood forecasting, Nord. Hydrol., 28, 169-188, 1997.

DeChant, C. M. and Moradkhani, H.: Radiance data assimilation for operational snow and streamflow forecasting, Adv. Water Resour. Res., 34, 351-364, 2011 a.

DeChant, C. M. and Moradkhani, H.: Improving the characterization of initial condition for ensemble streamflow prediction using data assimilation, Hydrol. Earth Syst. Sci., 15, 3399-3410, doi:10.5194/hess-15-3399-2011, 2011b.

DeChant, C. M. and Moradkhani, H.: Examining the effectiveness and robustness of data assimilation methods for calibration and quantification of uncertainty in hydrologic forecasting, Water Resour. Res., 48, W04518, doi:10.1029/2011WR011011, 2012.

Dee, D. P.: Bias and data assimilation, Q. J. Roy. Meteor. Soc., 131, 3323-3343, doi:10.1256/qj.05.137, 2005.

De Lannoy, G. J. M., Reichle, R. H., Houser, P. R., Pauwels, V. R., and Verhoest, N. E.: Correcting for forecast bias in soil moisture assimilation with the ensemble Kalman filter, Water Resour. Res., 43, W09410, doi:10.1029/2006WR005449, 2007.

De Lannoy, G. J. M., Reichle, R. H., Arsenault, K. R., Houser, P. R., Kumar, S., Verhoest, N. E. C., and Pauwels, V. R. N.: Multiscale assimilation of Advanced Microwave Scanning Radiometer.EOS snow water equivalent and Moderate Resolution Imaging Spectroradiometer snow cover fraction observations in northern Colorado, Water Resour. Res., 48, W01522, doi:10.1029/2011WR010588, 2012.

Demargne, J., Brown, J., Liu, Y., Seo, D. J., Wu, L., Toth, Z., and Zhu, Y.: Diagnostic verification of hydrometeorological and hydrologic ensembles, Atmos. Sci. Lett., 11, 114-122, 2010.

Dharssi, I., Bovis, K. J., Macpherson, B., and Jones, C. P.: Operational assimilation of ASCAT surface soil wetness at the Met Office, Hydrol. Earth Syst. Sci., 15, 2729-2746, doi:10.5194/hess15-2729-2011, 2011.

Diehl, M., Ferreau, H. J., and Haverbeke, N.: Efficient numerical methods for nonlinear MPC and moving horizon estimation, in: Lecture Notes in Control and Information Sciences 384, Nonlinear Model Predictive Control, edited by: Magni, L., Raimondo, D. M., and Allgöwer, F., 391-417, Springer-Verlag Berlin Heidelberg, 2009.

Dorigo, W. A., Scipal, K., Parinussa, R. M., Liu, Y. Y., Wagner, W., de Jeu, R. A. M., and Naeimi, V.: Error characterisation of global active and passive microwave soil moisture datasets, Hydrol. Earth Syst. Sci., 14, 2605-2616, doi:10.5194/hess-14-2605-
2010, 2010.

Drécourt, J.-P., Madsen, H., and Rosbjerg, D.: Calibration framework for a Kalman filter applied to a groundwater model, Adv. Water Resour., 29, 719-734, doi:16/j.advwatres.2005.07.007, 2006.

Durand, D., Andreadis, K. M., Alsdorf, D. E., Lettenmaier, D. P., Moller, D., and Wilson, M.: Estimation of bathymetric depth and slope from data assimilation of swath altimetry into a hydrodynamic model, Geophys. Res. Lett., 35, L20401, doi:10.1029/2008GL034150, 2008.

Durand, M., Kim, E. J., and Margulis, S. A.: Radiance assimilation shows promise for snowpack characterization, Geophys. Res. Lett., 36, L02503, doi:10.1029/2008GL035214, 2009.

Ehret, U., Zehe, E., Wulfmeyer, V., Warrach-Sagi, K., and Liebert, J.: HESS Opinions "Should we apply bias correction to global and regional climate model data?", Hydrol. Earth Syst. Sci., 16, 3391-3404, doi:10.5194/hess-16-3391-2012, 2012.

El Serafy, G. Y., Gerritsen, H., Hummel, S., Weerts, A. H., Mynett, A. E., and Tanaka, M.: Application of data assimilation in portable operational forecasting systems, the DATools assimilation environment, Ocean Dynam., 57, 485-499, 2007.

Entekhabi, D., Njoku, E., O.Neill, P., Kellogg, K., Crow, W., Edelstein, W., Entin, J., Goodman, S., Jackson, T., Johnson, J., Kimball, J., Piepmeier, J., Koster, R., McDonald, K., Moghaddam, M., Moran, S., Reichle, R., Shi, J. C., Spencer, M., Thurman, S., Tsang, L., and Van Zyl, J.: The Soil Moisture Active and Passive (SMAP) mission, P. IEEE, 98, 704-716, 2010.

Evensen, G.: Sequential data assimilation with a non-linear quasigeostrophic model using Monte Carlo methods to forecast error statistics, J. Geophys. Res., 97, 905-924, 1994.

Famiglietti, J., Murdoch, L., Lakshmi, V., and Hooper, R.: Community modeling in hydrologic science, Eos Trans. AGU, 89, 292, doi:10.1029/2008EO320005, 2008.

Farr, T. G., Rosen, P. A., Caro, E., Crippen, R., Duren, R., Hensley, S., Kobrick, M., Paller, M., Rodriguez, E., Roth, L., Seal, D., Shaffer, S., Shimada, J., Umland, J., Wernerm M., Oskin, M., Burbank, D., and Alsdorf, D.: The Shuttle Radar Topography Mission, Rev. Geophys., 45, RG2004, doi:10.1029/2005RG000183, 2007.

Fearnhead, P. and Clifford, P.: On-line inference for hidden Markov models via particle filters, J. R. Stat. Soc. B Met., 65, 887-899, 2003.

Fischer, C., Montmerle, T., Berre, L., Auger, L., and TEFNESCU, S. E.: An overview of the variational assimilation in the ALADIN/France numerical weather-prediction system, Q. J. Roy. Meteor. Soc., 131, 3477-3492, 2005

Forman, B. A., Reichle, R. H., and Rodell, M.: Assimilation of terrestrial water storage from GRACE in a snow dominated basin, Water Resour. Res., 48, W01507, doi:10.1029/2011WR011239, 2012.

Foster, J. L., Hall, D. K., Eylander, J. B., Riggs, G. A., Nghiem, S. V., Tedesco, M., Kim, E., Montesano, P. M., Kelly, R. E. J., Casey, K. A., and Choudhury, B.: A blended global snow product using visible, passive microwave and scatterometer satellite data, Int. J. Remote Sens., 32, 1371-1395, 2011.

Franssen, H. J. and Kinzelbach, W.: Real-time groundwater flow modeling with the Ensemble Kalman Filter: Joint estimation of states and parameters and the filter inbreeding problem, Water Resour. Res., 44, W09408, doi:10.1029/2007WR006505, 2008. 
Franssen, H. J., Gómez-Hernández, J., and Sahuquillo, A.: Coupled inverse modelling of groundwater flow and mass transport and the worth of concentration data, J. Hydrol., 281, 281-295, 2003.

Franssen, H. J. H., Brunner, P., Makobo, P., and Kinzelbach, W.: Equally likely inverse solutions to a groundwater flow problem including pattern information from remote sensing images, Water Resour. Res., 44, W01419, doi:10.1029/2007WR006097, 2008.

Franssen, H. J., Kaiser, H. P., Kuhlmann, U., Bauser, G., Stauffer, F., Müller, R., and Kinzelbach, W.: Operational realtime modeling with ensemble Kalman filter of variably saturated subsurface flow including stream-aquifer interaction and parameter updating, Water Resour. Res., 47, W02532, doi:10.1029/2010WR009480, 2011.

Frappart, F., Calmant, S., Cauhope, M., Seyler, F., and Cazenave, A.: Preliminary results of ENVISAT RA-2-derived water levels validation over the Amazon Basin, Remote Sens. Environ., 100, 252-264, 2006.

Gallagher, M. and Doherty, J.: Parameter estimation and uncertainty analysis for a watershed model, Environ. Model. Softw., 22, 1000-1020, 2007.

Georgakakos, K. P.: A generalized stochastic hydrometeorological model for flood and flash flood forecasting. 1 Formulation, Water Resour.Res., 22, 2083-2095, 1986a.

Georgakakos, K. P.: A generalized stochastic hydrometeorological model for flood and flash-flood forecasting: 2. Case studies, Water Resour. Res., 22, 2096-2106, 1986b.

Georgakakos, K. P., Seo, D. J., Gupta, H., Schaake, J., and Butts, M. B.: Towards the characterization of streamflow simulation uncertainty through multimodel ensembles, J. Hydrol., 298, 222-241, 2004.

Giustarini, L., Matgen, P., Hostache, R., Montanari, M., Plaza, D., Pauwels, V. R. N., De Lannoy, G. J. M., De Keyser, R., Pfister, L., Hoffmann, L., and Savenije, H. H. G.: Assimilating SARderived water level data into a hydraulic model: a case study, Hydrol. Earth Syst. Sci., 15, 2349-2365, doi:10.5194/hess-152349-2011, 2011.

Glanzmann, G., von Siebenthal, M., Geyer, T., Papafotiou, G., and Morari, M.: Supervisory water level control for cascaded river power plants, in Proceedings of the Hydropower Conference, Stavanger, Norway, 2005.

Götzinger, J. and Bárdossy, A.: Generic error model for calibration and uncertainty estimation of hydrological models, Water Resour. Res., 44, W00B0, doi:200810.1029/2007WR006691, 2008.

Gregersen, J., Gijsbers, P., and Westen, S.: OpenMI: Open modelling interface, J. Hydroinform., 9, 175-191, 2007.

Gupta, H. V., Sorooshian, S., and Yapo, P. O.: Toward improved calibration of hydrologic models: Multiple and noncommensurable measures of information, Water Resour. Res., 34, 751-763, 1998.

Gupta, H. V., Wagener, T., and Liu, Y.: Reconciling theory with observations: elements of a diagnostic approach to model evaluation, Hydrol. Process., 22, 3802-3813, 2008.

Hagedorn, R., Doblas-Reyes, F. J., and Palmer, T. N.: The rationale behind the success of multi-model ensembles in seasonal forecasting .I. Basic concept, Tellus A, 57, 219-233, 2005.

Hall, D. K., Riggs, G. A., Salomonson, V. V., DiGirolamo, N. E., and Bayr, K. J.: MODIS snow-cover products, Remote Sens. Environ., 83, 181-194, 2002.
Hall, D. K., Riggs, G. A., Foster, J. L., and Kumar, S. V.: Development and evaluation of a cloud-gap-filled MODIS daily snowcover product, Remote Sens. Environ., 114, 496-503, 2010.

Hong, Y., Hsu, K., Moradkhani, H., and Sorooshian, S.: Uncertainty Quantification of Satellite Precipitation Estimation and Monte Carlo Assessment of the Error Propagation into Hydrologic Response, Water Resour. Res., 42, W08421, doi:10.1029/2005WR004398, 2006.

Hossain, F. and Huffman, G. J.: Investigating error metrics for satellite rainfall data at hydrologically relevant scales, J. Hydrometeorol., 9, 563-575, 2008.

Houser, P. R., Shuttleworth, W. J., Famiglietti, J. S., Gupta, H. V., Syed, K. H., and Goodrich, D. C.: Integration of soil moisture remote sensing and hydrologic modeling using data assimilation, Water Resour. Res., 34, 3405-3420, 1998.

Hsu, K.-L., Moradkhani, H., and Sorooshian, S.: A sequential Bayesian approach for hydrologic model selection and prediction, Water Resour. Res., 45, W00B12, doi:10.1029/2008WR006824, 2009.

Huard, D. and Mailhot, A.: A Bayesian perspective on input uncertainty in model calibration: Application to hydrological model "abc", Water Resour. Res., 42, W07416, doi:10.1029/2005WR004661, 2006.

Jeu, R. A.: Retrieval of land surface parameters using passive microwave remote sensing, Ph.D. Thesis, Vrije Universiteit Amsterdam, The Netherlands, 144 pp., 2003.

Julier, S. J. and Uhlmann, J. K.: A new extension of the Kalman filter to nonlinear systems, P. SPIE, 3068, 182-193, doi:10.1117/12.280797, 1997.

Kalman, R. E.: A new approach to linear filtering and prediction problems, Transactions of the ASME-Journal of Basic Engineering, 82, 35-45, 1960.

Kavetski, D., Kuczera, G., and Franks, S. W.: Bayesian analysis of input uncertainty in hydrological modeling: 1 . Theory, Water Resour. Res., 42, W03407, doi:10.1029/2005WR004368, 2006a.

Kavetski, D., Kuczera, G., and Franks, S. W.: Bayesian analysis of input uncertainty in hydrological modeling: 2. Application, Water Resour. Res., 42, W03408, doi:10.1029/2005WR004376, 2006 b.

Kearney, M., Cantoni, M., and Dower, P. M.: Model predictive control for systems with scheduled load and its application to automated irrigation channels, in IEEE International Conference on Networking, Sensing and Control (ICNSC), 186-191, IEEE, 2011.

Kelly, R.: The AMSR-E snow depth algorithm: description and initial results, Journal of the Remote Sensing Society of Japan, 29, 307-317, 2009.

Kerr, Y. H. and Levine, D. M.: Guest editorial foreword to the special issue on the Soil Moisture and Ocean Salinity (SMOS) mission, IEEE T. Geosci. Remote, 46, 583-584, 2008.

Kirk, D. E.: Optimal control theory: an introduction, Dover Pubs., 2004.

Kitanidis, P. K. and Bras, R.: Real-time forecasting with a conceptual hydrological model. 1. Analysis of uncertainty, Water Resour. Res., 16, 1025-1033, 1980.

Kolberg, S. and Gottschalk, L.: Interannual stability of grid cell snow depletion curves as estimated from MODIS images, Water Resour. Res., 46, W11555, doi:10.1029/2008WR007617, 2010. 
Komma, J., Blöschl, G., and Reszler, C.: Soil moisture updating by Ensemble Kalman Filtering in real-time flood forecasting, J. Hydrol., 357, 228-242, 2008.

Krishnamurti, T., Kishtawal, C., LaRow, T. E., Bachiochi, D. R., Zhang, Z., Williford, C. E., Gadgil, S., and Surendran, S.: Improved weather and seasonal climate forecasts from multimodel superensemble, Science, 285, 1548-1550, doi:10.1126/science.285.5433.1548, 1999.

Krzysztofowicz, R. and Maranzano, C. J.: Hydrologic uncertainty processor for probabilistic stage transition forecasting, J. Hydrol., 293, 57-73, doi:10.1016/j.jhydrol.2004.01.003, 2004.

Kuchment, L. S., Romanov, P., Gelfan, A. N., and Demidov, V. N.: Use of satellite-derived data for characterization of snow cover and simulation of snowmelt runoff through a distributed physically based model of runoff generation, Hydrol. Earth Syst. Sci., 14, 339-350, doi:10.5194/hess-14-339-2010, 2010.

Kuczera, G. and Franks, S. W.: On the testing of hydrological models: falsification or fortification, in Mathematical models of watershed hydrology, Littleton, CO: Water Resource Publications, 141-186, 2002.

Kuczera, G., Kavetski, D., Franks, S., and Thyer, M.: Towards a Bayesian total error analysis of conceptual rainfall-runoff models: Characterising model error using storm-dependent parameters, J. Hydrol., 331, 161-177, 2006.

Kumar, S. V., Peters-Lidard, C. D., Tian, Y., Houser, P. R., Geiger, J., Olden, S., Lighty, L., Eastman, J. L., Doty, B., Dirmeyer, P., Adams, J., Mitchell, K., Wood, E. F., and Sheffield, J.: Land information system: An interoperable framework for high resolution land surface modeling, Environ. Model. Softw., 21, 14021415, 2006.

Kumar, S. V., Reichle, R. H., Peters-Lidard, C. D., Koster, R. D., Zhan, X., Crow, W. T., Eylander, J. B., and Houser, P. R.: A land surface data assimilation framework using the land information system: Description and applications, Adv. Water Resour., 31, 1419-1432, 2008a.

Kumar, S. V., Peters-Lidard, C., Tian, Y., Reichle, R., Geiger, J., Alonge, C., Eylander, J., and Houser, P.: An integrated hydrologic modeling and data assimilation framework, Computer, 41, 52-59, 2008 b.

Kumar, S. V., Reichle, R. H., Koster, R. D., Crow, W. T., and PetersLidard, C. D.: Role of subsurface physics in the assimilation of surface soil moisture observations, J. Hydrometeorol., 10, 1534 1547, doi:10.1175/2009JHM1134.1, 2009.

Lee, H., Seo, D.-J., and Koren, V.: Assimilation of streamflow and in-situ soil moisture data into operational distributed hydrologic models: Effects of uncertainties in the data and initial model soil moisture states, Adv. Water Resour., 34, 1597-1615, 2011.

Lee, H., Seo, D.-J., Liu, Y., Koren, V., McKee, P., and Corby, R.: Variational assimilation of streamflow into operational distributed hydrologic models: effect of spatiotemporal scale of adjustment, Hydrol. Earth Syst. Sci., 16, 2233-251, doi:10.5194/hess-16-2233-2012, 2012.

Lee, S., Klein, A. G., and Over, T. M.: A comparison of MODIS and NOHRSC snow-cover products for simulating streamflow using the Snowmelt Runoff Model, Hydrol. Process., 19, 2951-2972, 2005.

Lees, M., Young, P. C., Ferguson, S., Beven, K. J., and Burns, J.: An adaptive flood warning scheme for the River Nith at Dumfries, River Flood Hydraulics, Wiley, Chichester, 65-75, 1994.
Leisenring, M. and Moradkhani, H.: Snow water equivalent prediction using Bayesian data assimilation methods, Stoch. Env. Res. Risk A., 25, 1-18, 2011.

Leisenring, M. and Moradkhani, H.: Analyzing the uncertaintyof suspended sediment load prediction using sequential MonteCarlo methods, J. Hydrol., 468-469, 268-282, 2012.

Li, B., Toll, D., Zhan, X., and Cosgrove, B.: Improving estimated soil moisture fields through assimilation of AMSR-E soil moisture retrievals with an ensemble Kalman filter and a mass conservation constraint, Hydrol. Earth Syst. Sci., 16, 105-119, doi:10.5194/hess-16-105-2012, 2012.

Li, L., Gaiser, P. W., Gao, B. C., Bevilacqua, R. M., Jackson, T. J., Njoku, E. G., Rudiger, C., Calvet, J. C., and Bindlish, R.: WindSat global soil moisture retrieval and validation, IEEE T. Geosci. Remote, 48, 2224-2241, 2010.

Li, Z. and Navon, I. M.: Optimality of variational data assimilation and its relationship with the Kalman filter and smoother, Q. J. Roy. Meteor. Soc., 127, 661-683, 2001.

Linke, H., Karimanzira, D., Rauschenbach, T., and Pfutzenreuter, T.: Flash flood prediction for small rivers, in 2011 IEEE International Conference on Networking, Sensing and Control (ICNSC), 86-91, IEEE, 2011.

Liston, G. E. and Hiemstra, C. A.: A simple data assimilation system for complex snow distributions (SnowAssim), J. Hydrometeorol., 9, 989-1004, 2008.

Liu, J. S. and Chen, R.: Sequential Monte Carlo methods for dynamic systems, J. Am. Stat. Assoc., 93, 1032-1044, 1998.

Liu, Y. and Gupta, H. V.: Uncertainty in hydrologic modeling: Toward an integrated data assimilation framework, Water Resour. Res., 43, W07401, doi:10.1029/2006WR005756, 2007.

Liu, Y., Brown, J., Demargne, J., and Seo, D.-J.: A wavelet-based approach to assessing timing errors in hydrologic predictions, J. Hydrol., 397, 210-224, 2011.

Liu, Y., Dorigo, W. A., Parinussa, R. M., de Jeu, R. A. M., Wagner, W., McCabe, M. F., Evans, J. P., van Dijk, A. I. J. M.: Trend-preserving blending of passive and active microwave soil moisture retrievals, Remote Sens. Environ., 123, 280-297, 10.1016/j.rse.2012.03.014, 2012.

Lorenc, A. C. and Rawlins, F.: Why does 4D-Var beat 3D-Var?, Q. J. Roy. Meteor. Soc., 131, 3247-3257, 2005.

Lü, H., Yu, Z., Zhu, Y., Drake, S., Hao, Z., and Sudicky, E. A.: Dual state-parameter estimation of root zone soil moisture by optimal parameter estimation and extended Kalman filter data assimilation, Adv. Water Resour., 34, 395-406, doi:10.1016/j.advwatres.2010.12.005, 2011.

Madsen, H., Rosbjerg, D., Damgard, J., and Hansen, F. S.: Data assimilation into MIKE 11 flood forecasting system using Kalman filtering, Water Resources Systems - Hydrological Risk, Management and Development, IAHS Publ no. 281, 75-81, 2003.

Masahiro, K., Liu, Q., Treadon, R., and Derber, J. C.: Impact study of AMSR-E radiances in the NCEP Global Data Assimilation System, Mon. Weather Rev., 136, 541-559, doi:10.1175/2007MWR2147.1, 2008.

Mason, S. J. and Mimmack, G. M.: Comparison of some statistical methods of probabilistic forecasting of ENSO, J. Climate, 15 , 8-29, 2002.

Matgen, P., Montanari, M., Hostache, R., Pfister, L., Hoffmann, L., Plaza, D., Pauwels, V. R. N., De Lannoy, G. J. M., De Keyser, R., and Savenije, H. H. G.: Towards the sequential assimilation 
of SAR-derived water stages into hydraulic models using the Particle Filter: proof of concept, Hydrol. Earth Syst. Sci., 14, 17731785, doi:10.5194/hess-14-1773-2010, 2010.

McEnery, J., Ingram, J., Duan, Q., Adams, T., and Anderson, L.: NOAA.S Advanced Hydrologic Prediction Service: Building Pathways for Better Science in Water Forecasting, B. Am. Meteorol. Soc., 86, 375-385, doi:10.1175/BAMS-86-3-375, 2005.

McLaughlin, D.: An integrated approach to hydrologic data assimilation: interpolation, smoothing, and filtering, Adv. Water Res., 25, 1275-1286, 2002.

McMillan, H., Jackson, B., Clark, M., Kavetski, D., and Woods, R.: Rainfall uncertainty in hydrological modelling: An evaluation of multiplicative error models, J. Hydrol., 400, 83-94, doi:10.1016/j.jhydrol.2011.01.026, 2011.

Mo, X., Chen, J. M., Ju, W., and Black, T. A.: Optimization of ecosystem model parameters through assimilating eddy covariance flux data with an Ensemble Kalman filter, Ecol. Model., 217, 157-173, 2008.

Montanari, M., Hostache, R., Matgen, P., Schumann, G., Pfister, L., and Hoffmann, L.: Calibration and sequential updating of a coupled hydrologic-hydraulic model using remote sensingderived water stages, Hydrol. Earth Syst. Sci., 13, 367-380, doi:10.5194/hess-13-367-2009, 2009.

Montzka, C., Moradkhani, H., Weihermuller, L., Franssen, H. J. H., Canty, M., and Vereecken, H.: Hydraulic parameter estimation by remotely-sensed top soil moisture observations with the particle filter, J. Hydrol., 399, 410-421, 2011.

Moore, R. J.: The PDM rainfall-runoff model, Hydrol. Earth Syst. Sci., 11, 483-499, doi:10.5194/hess-11-483-2007, 2007.

Moore, R. V. and Tindall, C. I.: An overview of the open modelling interface and environment (the OpenMI), Environ. Sci. Policy, 8, 279-286, 2005.

Moradkhani, H. and Sorooshian, S.: General review of rainfallrunoff modeling: model calibration, data assimilation, and uncertainty analysis, in Hydrological Modeling and Water Cycle, Coupling of the Atmospheric and Hydrological Models, Springer, Water Science and Technology Library, 63, 1-24, doi:10.1007/978-3-540-77843-1_1, 2008.

Moradkhani, H., Hsu, K., Gupta, H. V., and Sorooshian, S.: Uncertainty asssessment of hydrologic model states and parameters: sequential data assimilation using particle filter, Water Resour. Res., 41, W05012, doi:10.1029/2004WR003604, 2005a.

Moradkhani, H., Sorooshian, S., Gupta, H. V., and Houser, P.: Dual state-parameter estimation of hydrological models using Ensemble Kalman filter, Adv. Water Resour., 28, 135-147, 2005b.

Moradkhani, H., Hsu, K., Hong, Y., and Sorooshian, S.: Investigating the impact of remotely sensed precipitation and hydrologic model uncertainties on the ensemble streamflow forecasting, Geophys. Res. Lett., 33, L12401, doi:10.1029/2006GL026855, 2006.

Moradkhani, H., DeChant C. M., and Sorooshian, S.: Evolution of ensemble data assimilation for uncertainty quantification using the Particle Filter-Markov Chain Monte Carlo method, Water Resour. Res., in review, 2012.

Naevdal, G., Johnsen, L., Aanonsen, S., and Vefring, E.: Reservoir monitoring and continuous model updating using ensemble Kalman filter, SPE Journal, 10, 66-74, 2003.

Nagarajan, K., Judge, J., Graham, W. D., and Monsivais-Huertero, A.: Particle Filter-based assimilation algorithms for improved es- timation of root-zone soil moisture under dynamic vegetation conditions, Adv. Water Resour., 34, 433-447, 2010.

National Research Council (US): Completing the Forecast: Characterizing and Communicating Uncertainty for Better Decisions Using Weather and Climate Forecasts, Natl. Academy Pr., 2006.

National Research Council (US): Earth science and applications from space: national imperatives for the next decade and beyond, Natl. Academy Pr., 2007.

Neal, J. C., Atkinson, P. M., and Hutton, C. W.: Flood inundation model updating using an ensemble Kalman filter and spatially distributed measurements, J. Hydrol., 336, 401-415, 2007.

Neal, J., Schumann, G., Bates, P., Buytaert, W., Matgen, P., and Pappenberger, F.: A data assimilation approach to discharge estimation from space, Hydrol. Process., 23, 3641-3649, 2009.

Nelly, J.-B., Pierre-Olivier, M., Christophe, D., and Jacques, S.: Data assimilation for real-time estimation of hydraulic states and unmeasured perturbations in a 1D hydrodynamic model, Journal of Mathematics and Computers in Simulation, 81, 2201-2214, doi:10.1016/j.matcom.2010.12.021, 2011.

Negenborn, R. R., van Overloop, P. J., Keviczky, T., and De Schutter, B.: Distributed model predictive control of irrigation canals, Networks and Heterogeneous Media (NHM), 4, 359-380, 2009.

Nerger, L., Hiller, W., and Schröter, J.: PDAF-The Parallel Data Assimilation Framework: Experiences with Kalman Filtering, in: Use of High Performance Computing in MeteorologyProceedings of the 11, ECMWF Workshop, 63-83, 2005.

Neuman, S. P.: Maximum likelihood Bayesian averaging of uncertain model predictions, Stoch. Env. Res. Risk A., 17, 291-305, 2003.

Nie, S., Zhu, J., and Luo, Y.: Simultaneous estimation of land surface scheme states and parameters using the ensemble Kalman filter: identical twin experiments, Hydrol. Earth Syst. Sci., 15, 2437-2457, doi:10.5194/hess-15-2437-2011, 2011.

Niu, G.-Y., Yang, Z.-L., Mitchell, K. E., Chen, F., Ek, M. B., Barlage, M., Manning, K., Niyogi, D., Rosero, E., Tewari, M., and Xia, Y.: The community Noah land surface model with multiparameterization options (Noah-MP): 1. Model description and evaluation with local-scale measurements, J. Geophys. Res., 116, D12109, doi:10.1029/2010JD015139, 2011.

Noh, S. J., Tachikawa, Y., Shiiba, M., and Kim, S.: Applying sequential Monte Carlo methods into a distributed hydrologic model: lagged particle filtering approach with regularization, Hydrol. Earth Syst. Sci., 15, 3237-3251, doi:10.5194/hess-15-32372011, 2011.

Ott, E., Hunt, B. R., Szunyogh, I., Zimin, A. V., Kostelich, E. J., Corazza, M., Kalnay, E., Patil, D., and Yorke, J. A.: A local ensemble Kalman filter for atmospheric data assimilation, Tellus A, 56, 415-428, 2004.

Ottlé, C. and Vidal-Madjar, D.: Assimilation of soil moisture inferred from infrared remote sensing in a hydrological model over the HAPEX-MOBILHY region, J. Hydrol., 158, 241-264, 1994.

Owe, M., de Jeu, R., and Holmes, T.: Multisensor historical climatology of satellite-derived global land surface moisture, J. Geophys. Res., 113, F01002, doi:10.1029/2007JF000769, 2008.

Palmer, T. N., Branković, Č, and Richardson, D. S.: A probability and decision-model analysis of PROVOST seasonal multi-model ensemble integrations, Q. J. Roy. Meteor. Soc., 126, 2013-2033, 2000. 
Pan, M. and Wood, E. F.: A multiscale ensemble filtering system for hydrologic data assimilation. Part II: Application to land surface modeling with satellite rainfall forcing, J. Hydrometeorol., 10, 1493-1506, 2009.

Pappenberger, F. and Beven, K. J.: Ignorance is bliss: Or seven reasons not to use uncertainty analysis, Water Resour. Res., 42, W05302, doi:10.1029/2005WR004820, 2006.

Pappenberger, F., Bartholmes, J., Thielen, J., Cloke, H. L., Buizza, R., and de Roo, A.: New dimensions in early flood warning across the globe using grand-ensemble weather predictions, Geophys. Res. Lett., 35, L10404, doi:10.1029/2008GL033837, 2008.

Pappenberger, F., Thielen, J., and Del Medico, M.: The impact of weather forecast improvements on large scale hydrology: analysing a decade of forecasts of the European Flood Alert System, Hydrol. Process., 25, 1091-1113, 2011.

Parajka, J. and Blösch, G.: The value of MODIS snow cover data in validating and calibrating conceptual hydrologic models, J. Hydrol., 358, 240-258, 2008.

Parrish, M., Moradkhani, H., and DeChant, C. M. Towards reduction of model uncertainty: integration of Bayesian model averaging and data assimilation, Water Resour. Res., 48, W03519, doi:10.1029/2011WR011116, 2012.

Pathe, C., Wagner, W., Sabel, D., Doubkova, M., and Basara, J. B.: Using ENVISAT ASAR global mode data for surface soil moisture retrieval over Oklahoma, USA, IEEE T. Geosci. Remote, 47, 468-480, 2009.

Pauwels, V. R. and De Lannoy, G. J.: Improvement of modeled soil wetness conditions and turbulent fluxes through the assimilation of observed discharge, J. Hydrometeorol., 7, 458-477, 2006.

Pauwels, V. R., Hoeben, R., Verhoest, N. E., and De Troch, F. P.: The importance of the spatial patterns of remotely sensed soil moisture in the improvement of discharge predictions for smallscale basins through data assimilation, J. Hydrol., 251, 88-102, 2001.

Peters-Lidard, C. D., Kumar, S. V., Mocko, D. M., and Tian, Y.: Estimating evapotranspiration with land data assimilation systems, Hydrol. Process., 25, 3979-3992, 2011.

Piani, C., Weedon, G., Best, M., Gomes, S., Viterbo, P., Hagemann, S., and Haerter, J.: Statistical bias correction of global simulated daily precipitation and temperature for the applicationof hydrological models, J. Hydrol., 395, 199-215, doi:10.1016/j.jhydrol.2010.10.024, 2010.

Plaza, D. A., De Keyser, R., De Lannoy, G. J. M., Giustarini, L., Matgen, P., and Pauwels, V. R. N.: The importance of parameter resampling for soil moisture data assimilation into hydrologic models using the particle filter, Hydrol. Earth Syst. Sci., 16, 375390, doi:10.5194/hess-16-375-2012, 2012.

Parajka, J., Naeimi, V., Blöschl, G., Wagner, W., Merz, R., and Scipal, K.: Assimilating scatterometer soil moisture data into conceptual hydrologic models at the regional scale, Hydrol. Earth Syst. Sci., 10, 353-368, doi:10.5194/hess-10-353-2006, 2006.

Rabier, F.: Overview of global data assimilation developments in numerical weather-prediction centres, Q. J. Roy. Meteor. Soc., 131, 3215-3233, 2005.

Rakovec, O., Weerts, A. H., Hazenberg, P., Torfs, P. J. J. F., and Uijlenhoet, R.: State updating of a distributed hydrological model with Ensemble Kalman Filtering: effects of updating frequency and observation network density on forecast accuracy, Hydrol. Earth Syst. Sci., 16, 3435-3449, doi:10.5194/hess-16-
3435-2012, 2012a.

Rakovec, O., Hazenberg, P., Torfs, P. J. J. F., Weerts, A. H., and Uijlenhoet, R.: Generating spatial precipitation ensembles: impact of temporal correlation structure, Hydrol. Earth Syst. Sci., 16, 3419-3434, doi:10.5194/hess-16-3419-2012, 2012b.

Ramamoorthi, A. S.: Snow-melt run-off studies using remote sensing data, Sadhana, 6, 279-286, 1983.

Raso, L., Schwanenberg, D., van der Giesen, N., and van Overloop, P. J.: Tree-Scenario Based Model Predictive Control, in Geophysical Research Abstracts, 12, EGU2010-3178-1, 2010

Reggiani, P. and Weerts, A. H.: A Bayesian approach to decision-making under uncertainty: An application to realtime forecasting in the river Rhine, J. Hydrol., 356, 56-69, doi:10.1016/j.jhydrol.2008.03.027, 2008.

Reggiani, P., Renner, M., Weerts, A. H., and van Gelder, P.: Uncertainty assessment via Bayesian revision of ensemble streamflow predictions in the operational river Rhine forecasting system, Water Resour. Res., 45, W02428, doi:10.1029/2007WR006758, 2009.

Regonda, S. K., Rajagopalan, B., Clark, M., and Zagona, E.: A multimodel ensemble forecast framework: Application to spring seasonal flows in the Gunnison River Basin, Water Resour. Res., 42, W09404, doi:10.1029/2005WR004653, 2006.

Reichle, R. H.: Data assimilation methods in the Earth sciences, Adv. Water Resour., 31, 1411-1418, doi:10.1016/j.advwatres.2008.01.001, 2008.

Reichle, R. H., Walker, J. P., Koster, R. D., and Houser, P. R.: Extended versus Ensemble Kalman Filtering for Land Data Assimilation, J. Hydrometeorol., 3, 728-740, 2002.

Reichle, R. H., Koster, R. D., Dong, J., and Berg, A. A.: Global Soil Moisture from Satellite Observations, Land Surface Models, and Ground Data: Implications for Data Assimilation, J. Hydrometeor, 5, 430-442, 2004.

Reichle, R. H., Crow, W. T., and Keppenne, C. L.: An adaptive ensemble Kalman filter for soil moisture data assimilation, Water Resour. Res., 44, W03423, doi:200810.1029/2007WR006357, 2008.

Reichle, R. H., Kumar, S. V., Mahanama, S. P. P., Koster, R. D., and Liu, Q.: Assimilation of Satellite-Derived Skin Temperature Observations into Land Surface Models, J. Hydrometeorol., 11, 1103-1122, doi:10.1175/2010JHM1262.1, 2010.

Renard, B., Kavetski, D., Kuczera, G., Thyer, M., and Franks, S. W.: Understanding predictive uncertainty in hydrologic modeling: The challenge of identifying input and structural errors, Water Resour. Res., 46, W05521, doi:10.1029/2009WR008328, 2010.

Ricci, S., Piacentini, A., Thual, O., Le Pape, E., and Jonville, G.: Correction of upstream flow and hydraulic state with data assimilation in the context of flood forecasting, Hydrol. Earth Syst. Sci., 15, 3555-3575, doi:10.5194/hess-15-3555-2011, 2011.

Rodell, M. and Houser, P. R.: Updating a land surface model with MODIS-derived snow cover, J. Hydrometeorol., 5, 1064-1075, 2004.

Roest, M. and Vollebregt, E.: Parallel Kalman filtering for a shallowwater flow model, in: Parallel Computational Fluid Dynamics-Practice and Theory, edited by: Wilders, P., Ecer, A., Periaux, J., Satofuka, N., and Fox, P., 301-308, Elsevier Science B.V., Amsterdam, The Netherlands, 2002.

Rojas, R., Feyen, L., Dosio, A., and Bavera, D.: Improving panEuropean hydrological simulation of extreme events through 
statistical bias correction of RCM-driven climate simulations, Hydrol. Earth Syst. Sci., 15, 2599-2620, doi:10.5194/hess-152599-2011, 2011.

Rungo, M., Refsgaard, J., and Havno, K.: The updating procedure in the MIKE 11 modelling system for real-time forecasting, in Proceedings of the International Symposium for Hydrological Applications of Weather Radar, University of Salford, 14-17, 1989.

Ryu, D., Crow, W. T., and Zhan, X.: Correcting Unintended Perturbation Biases in Hydrologic Data Assimilation, J. Hydrometeorol., 10, 734-750, 2009.

Sahin, A.: Model predictive control for large scale systems: two industrial applications, PhD thesis, ETH Zurich, doi:10.3929/ethza-006086198, 2009.

Sahuquillo, A., Capilla, J. E., Gómez-Hernández, J. J., and Andreu, J.: Conditional simulation of transmissivity fields honoring piezometric data, Hydraulic engineering software IV, Hyd. Eng. Sof., 2, 201-214, 1992.

Salamon, P. and Feyen, L.: Disentangling uncertainties in distributed hydrological modeling using multiplicative error models and sequential data assimilation, Water Resour. Res., 46, W12501, doi:10.1029/2009WR009022, 2010.

Schaake, J., Franz, K., Bradley, A., and Buizza, R.: The Hydrologic Ensemble Prediction EXperiment (HEPEX), Hydrol. Earth Syst. Sci. Discuss., 3, 3321-3332, doi:10.5194/hessd-3-33212006, 2006.

Schumann, G., Bates, P. D., Horritt, M. S., Matgen, P., and Pappenberger, F.: Progress in integration of remote sensing derived flood extent and stage data and hydraulic models, Rev. Geophys, 47, RG4001, doi:10.1029/2008RG000274, 2009.

Schutz, B. E., Zwally, H. J., Shuman, C. A., Hancock, D., and DiMarzio, J. P.: Overview of the ICESat mission, Geophys. Res. Lett., 32, L21S01, doi:10.1029/2005GL024009, 2005.

Schwanenberg, D., van Breukelen, A., and Hummel, S.: Data assimilation for supporting optimum control in large-scale river networks, in 2011 IEEE International Conference on Networking, Sensing and Control (ICNSC), 98-103, 2011.

Seo, D.-J., Koren, V., and Cajina, N.: Real-time variational assimilation of hydrologic and hydrometeorological data into operational hydrologic forecasting, J. Hydrometeorol., 4, 627-641, 2003.

Seo, D.-J., Herr, H. D., and Schaake, J. C.: A statistical postprocessor for accounting of hydrologic uncertainty in short-range ensemble streamflow prediction, Hydrol. Earth Syst. Sci. Discuss., 3, 1987-2035, doi:10.5194/hessd-3-1987-2006, 2006.

Seo, D.-J., Cajina, L., Corby, R., and Howieson, T.: Automatic state updating for operational streamflow forecasting via variational data assimilation, J. Hydrol., 367, 255-275, doi:10.1016/j.jhydrol.2009.01.019, 2009.

Setz, C., Heinrich, A., Rostalski, P., Papafotiou, G., and Morari, M.: Application of model predictive control to a cascade of river power plants, in Proceedings of the IFAC World Congress, 2008.

Shamir, E., Lee, B.-J., Bae, D.-H., and Georgakakos, K. P.: Flood Forecasting in Regulated Basins Using the Ensemble Extended Kalman Filter with the Storage Function Method, J. Hydrol. Eng., 15, 1030, doi:10.1061/(ASCE)HE.1943-5584.0000282, 2010.

Shiiba, M., Laurenson, X., and Tachikawa, Y.: Real-time stage and discharge estimation by a stochastic-dynamic flood routing model, Hydrol. Process., 14, 481-495, 2000.
Slater, A. G. and Clark, M. P.: Snow data assimilation via an ensemble Kalman filter, J. Hydrometeorol., 7, 478-493, 2006.

Smith, M. B., Laurine, D. P., Koren, V. I., Reed, S. M., and Zhang, Z.: Hydrologic Model Calibration in the National Weather Service, in: Calibration of Watershed Models, Water Science and Application 6, edited by: Duan, Q., Gupta, H., Sorooshian, S., Rousseau, A., and Turcotte, R., AGU Press, Washington, D.C., 133-152, 2003.

Smith, P. J., Beven, K. J., Weerts, A. H., and Leedal, D.: Adaptive correction of deterministic models to produce probabilistic forecasts, Hydrol. Earth Syst. Sci., 16, 2783-2799, doi:10.5194/hess16-2783-2012, 2012.

Snyder, C., Bengtsson, T, Bickel, P., and Anderson, J.: Obstacles to high-dimensional particle filtering, Mon. Weather Rev., 136, 4629-4640, 2008.

Sorooshian, S., AghaKouchak, A., Arkin, P., Eylander, J., Foufoula-Georgiou, E., Harmon, R., Hendrickx, J.M.H., Imam, B., Kuligowski, R., Skahill, B., and Skofronock-Jackson, G.: Advanced concepts on remote sensing of precipitation at multiple scales, B. Am. Meteor. Soc., 92, 1353-1357, doi:10.1175/2011BAMS3158.1, 2011.

Steiner, M.: Uncertainty of estimates of monthly areal rainfall for temporally sparse remote observations, Water Resour. Res., 32, 373-388, 1996.

Stroud, J. R., Lesht, B. M., Schwab, D. J., Beletsky, D., and Stein, M. L.: Assimilation of satellite images into a sediment transport model of Lake Michigan, Water Resour. Res., 45, W02419, doi:10.1029/2007WR006747, 2009.

Su, H., Yang, Z. L., Dickinson, R. E., Wilson, C. R. and Niu, G. Y.: Multisensor snow data assimilation at the continental scale: The value of Gravity Recovery and Climate Experiment terrestrial water storage information, J. Geophys. Res., 115, D10104, doi:10.1029/2009JD013035, 2010.

Sun, A. Y., Morris, A. P., and Mohanty, S.: Sequential updating of multimodal hydrogeologic parameter fields using localization and clustering techniques, Water Resour. Res., 45, W07424, doi:10.1029/2008WR007443, 2009.

Szunyogh, I., Kostelich, E. J., Gyarmati, G., Kalnay, E., Hunt, B. R., Ott, E., Satterfield, E., and Yorke, J. A.: A local ensemble transform Kalman filter data assimilation system for the NCEP global model, Tellus A, 60, 113-130, 2008.

Tapley, B. D., Bettadpur, S., Ries, J. C., Thompson, P. F., and Watkins, M. M.: GRACE measurements of mass variability in the Earth system, Science, 305, 503, doi:10.1126/science.1099192, 2004.

Thielen, J., Bartholmes, J., Ramos, M.-H., and de Roo, A.: The European Flood Alert System - Part 1: Concept and development, Hydrol. Earth Syst. Sci., 13, 125-140, doi:10.5194/hess-13-1252009, 2009.

Thirel, G., Martin, E., Mahfouf, J.-F., Massart, S., Ricci, S., and Habets, F.: A past discharges assimilation system for ensemble streamflow forecasts over France - Part 1: Description and validation of the assimilation system, Hydrol. Earth Syst. Sci., 14, 1623-1637, doi:10.5194/hess-14-1623-2010, 2010a.

Thirel, G., Martin, E., Mahfouf, J.-F., Massart, S., Ricci, S., Regimbeau, F., and Habets, F.: A past discharge assimilation system for ensemble streamflow forecasts over France - Part 2: Impact on the ensemble streamflow forecasts, Hydrol. Earth Syst. Sci., 14, 1639-1653, doi:10.5194/hess-14-1639-2010, 2010b. 
Thyer, M., Renard, B., Kavetski, D., Kuczera, G., Franks, S., and Srikanthan, S.: Critical evaluation of parameter consistency and predictive uncertainty in hydrological modeling: A case study using Bayesian total error analysis, Water Resour. Res., 45, 22, doi:10.1029/2008WR006825, 2009.

Tian, Y. and Peters-Lidard, C. D.: A global map of uncertainties in satellite.based precipitation measurements, Geophys. Res. Lett., 37, L24407, doi:10.1029/2010GL046008, 2010.

Todini, E.: A model conditional processor to assess predictive uncertainty in flood forecasting, Int. J. River Basin Manag., 6, 123137, 2008.

Tracton, M. S. and McPherson, R. D.: On the impact of radiometric sounding data upon operational numerical weather prediction at NMC, Am. Meteorol. Soc., Bulletin, 58, 1201-1209, 1977.

Turner, M., Walker, J., and Oke, P.: Ensemble member generation for sequential data assimilation, Remote Sens. Environ., 112, 1421-1433, 2008.

Valstar, J. R., McLaughlin, D. B., Stroet, C. B. M. te, and Geer, F. C. van: A representer-based inverse method for groundwater flow and transport applications, Water Resour. Res., 40, W05116, doi:200410.1029/2003WR002922, 2004.

van Dijk, A. I. J. M. and Renzullo, L. J.: Water resource monitoring systems and the role of satellite observations, Hydrol. Earth Syst. Sci., 15, 39-55, doi:10.5194/hess-15-39-2011, 2011.

van Velzen, N. and Segers, A.: A problem-solving environment for data assimilation in air quality modelling, Environ. Model. Softw., 25, 277-288, 2010.

van Velzen, N. and Verlaan, M.: COSTA a problem solving environment for data assimilation applied for hydrodynamical modelling, Meteorologische Z., 16, 777-793, doi:10.1127/09412948/2007/0241, 2007.

Villarini, G. and Krajewski, W. F.: Empirically-based modeling of spatial sampling uncertainties associated with rainfall measurements by rain gauges, Adv. Water Resour., 31, 1015-1023, 2008.

Volkmann, T. H. M., Lyon, S. W., Gupta, H. V., and Troch, P. A.: Multicriteria design of rain gauge networks for flash flood prediction in semiarid catchments with complex terrain, Water Resour. Res., 46, W11554, doi:10.1029/2010WR009145, 2010.

van Overloop, P. J., Weijs, S., and Dijkstra, S.: Multiple model predictive control on a drainage canal system, Control Eng. Pract., 16, 531-540, 2008.

Vrugt, J. A., Gupta, H. V., Bouten, W., and Sorooshian, S.: A Shuffled Complex Evolution Metropolis algorithm for optimization and uncertainty assessment of hydrologic model parameters, Water Resour. Res., 39, 1201, doi:10.1029/2002WR001642, 2003.

Vrugt, J. A., Diks, C. G., Gupta, H. V., Bouten, W., and Verstraten, J. M.: Improved treatment of uncertainty in hydrologic modeling: Combining the strengths of global optimization and data assimilation, Water Resour. Res, 41, W01017, doi:10.1029/2004WR003059, 2005.

Vrugt, J. A., Gupta, H. V., Nualláin, B., and Bouten, W.: Real-Time Data Assimilation for Operational Ensemble Streamflow Forecasting, J. Hydrometeorol., 7, 548-565, doi:10.1175/JHM504.1, 2006.

Wächter, A. and Biegler, L. T.: On the implementation of an interior-point filter line-search algorithm for large-scale nonlinear programming, Math. Program., 106, 25-57, 2006.

Wang, D. and Cai, X.: Robust data assimilation in hydrological modeling-A comparison of Kalman and H-infinity filters, Adv.
Water Resour., 31, 455-472, 2008.

Weerts, A. H. and El Serafy, G. Y. H.: Particle filtering and ensemble Kalman filtering for state updating with hydrological conceptual rainfall-runoff models, Water Resour. Res., 42, W09403, doi:10.1029/2005WR004093, 2006.

Weerts, A. H. and Liu, Y.: Advances in Data Assimilation for Operational Hydrologic Forecasting, Eos Trans. AGU, 92(7), 2011.

Weerts, A. H., El Serafy, G. Y., Hummel, S., Dhondia, J., and Gerritsen, H.: Application of generic data assimilation tools (DATools) for flood forecasting purposes, Comput. Geosci., 36, 453-463, doi:10.1016/j.cageo.2009.07.009, 2010.

Weerts, A. H., Winsemius, H. C., and Verkade, J. S.: Estimation of predictive hydrological uncertainty using quantile regression: examples from the National Flood Forecasting System (England and Wales), Hydrol. Earth Syst. Sci., 15, 255-265, doi:10.5194/hess-15-255-2011, 2011.

Welles, E., Sorooshian, S., Carter, G., and Olsen, B.: Hydrologic verification: A call for action and collaboration, B. Am. Meteor. Soc., 88, 503, doi:10.1175/BAMS-88-4-503, 2007.

Werner, M., Cranston, M., Harrison, T., Whitfield, D., and Schellekens, J.: Understanding the value of radar rainfall nowcasts in flood forecasting and warning in flashy catchments, Meteorol. Appl., 16, 41-55, 2009.

Werner, M., Schellekens, J., Gijsbers, P., van Dijk, M., and van den Akker, O., Heynert, K.: The Delft-FEWS flow forecasting system, Environ. Model. Softw., in press, 2012.

Willems, P.: Stochastic description of the rainfall input errors in lumped hydrological models, Stoch. Env. Res. Risk A., 15, 132$152,2002$.

Xiong, X., Navon, I. M., and Uzunoglu, B.: A note on the particle filter with posterior Gaussian resampling, Tellus A, 58, 456-460, 2006.

Yirdaw, S. Z., Snelgrove, K. R., and Agboma, C. O.: GRACE satellite observations of terrestrial moisture changes for drought characterization in the Canadian Prairie, J. Hydrol., 356, 84-92, 2008.

Young, P. C.: Advances in real-time flood forecasting, Philos. T. Roy. Soc. Lond., 360, 1433-1450, 2002.

Zafra-Cabeza, A., Maestre, J. M., Ridao, M. A., Camacho, E. F., and Sanchez, L.: A hierarchical distributed model predictive control approach to irrigation canals: A risk mitigation perspective, J. Process Contr., 21, 787-799, doi:10.1016/j.jprocont.2010.12.012, 2011.

Zaitchik, B. F., Rodell, M., and Reichle, R. H.: Assimilation of GRACE terrestrial water storage data into a land surface model: results for the Mississippi river basin, J. Hydrometeorol., 9, 535548, doi:10.1175/2007JHM951.1, 2008.

Zhang, F., Zhang, M., and Hansen, J. A.: Coupling ensemble Kalman filter with four-dimensional variational data assimilation, Adv. Atmos. Sci., 26, 1-8, doi:10.1007/s00376-009-00018, 2009.

Zhou, H., Gómez-Hernández, J. J., Franssen, H. J. H., and Li, L.: An approach to handling non-Gaussianity of parameters and state variables in ensemble Kalman filtering, Adv. Water Resour., 34, 844-864, doi:10.1016/j.advwatres.2011.04.014, 2011.

Zreda, M., Desilets, D., Ferre, T. P. A., and Scott, R. L.: Measuringsoil moisture content non-invasively at intermediate spatial scale using cosmic-ray neutrons, Geophys. Res. Lett., 35, L21402, doi:10.1029/2008GL035655, 2008 